\title{
Entre la conservación del bosque y el crecimiento de la ciudad: las localidades rurales en el espacio periurbano del Huitepec en San Cristóbal de Las Casas, Chiapas, México*
}

\author{
Araceli Calderón Cisneros** \\ Lorena Soto Pinto*** \\ Erin Estrada Lugo****
}

El crecimiento urbano afecta las áreas agrícolas y forestales situadas en sus inmediaciones y transforma las formas tradicionales de control y uso de la tierra. Se cuenta con poca información acerca de las modalidades que toma este proceso en las ciudades medias, y menos aún si se le enfoca desde la perspectiva de los actores locales. Aqui se presenta un estudio de caso que analiza el crecimiento de la ciudad de San Cristóbal de Las Casas, Chiapas, sobre un espacio rural aledaño y sus efectos sobre las áreas forestales y agrícolas. Aun cuando existe un fuerte proceso de urbanización, marcado por el aumento de la población, la fragmentación de la propiedad de la tierra y la llegada de los servicios urbanos, se mantienen algunas áreas forestales en reservas naturales y en espacios asociados a usos agrícolas y urbanos, las cuales forman un paisaje agroforestal que provee recursos naturales y servicios ambientales a la población local y urbana, entre ellos sobresale la recarga de agua. Lo anterior parece corresponder a una nueva ruralidad en que se presenta la integración espacial de procesos socioambientales urbanos y rurales, donde el bosque y la agricultura tienen un sentido y un valor distintos para los actores ahi presentes, que en no pocas ocasiones están en contradicción.

* Las autoras agradecen al doctor José Luis Escalona sus acertados comentarios al presente trabajo; a Daniel Bojórquez y Elizabeth Suárez su apoyo en el levantamiento de entrevistas; a Emmanuel Valencia y Julio César Llanes, de LAIGE Ecosur, su respaldo y asesoría en la elaboración de mapas y el uso de imágenes satélite; a María Patrocinio, de Pronatura Sur, los polígonos de las áreas de reserva; y a la doctora Pedrero la información sobre las labores de San Cristóbal. La presente investigación es resultado de los estudios doctorales de Araceli Calderón, quien contó con una beca del Consejo Nacional de Ciencia y Tecnología. Para el trabajo de campo se contó con el financiamiento del Fondo Institucional de Fomento Regional para el Desarrollo Científico, Tecnológico y de Innovación de Conacyt dentro del proyecto Innovación Socioambiental para el Desarrollo en Áreas de Alta Pobreza y Biodiversidad de la Frontera Sur de México.

** El Colegio de la Frontera Sur, Unidad San Cristóbal. Correo electrónico: $<$ acalderon@ecosur.mx>.

*** El Colegio de la Frontera Sur, Unidad San Cristóbal. Correo electrónico: $<$ lsoto@ecosur.mx $>$.

**** El Colegio de la Frontera Sur, Unidad San Cristóbal. Correo electrónico: $<$ eestrada@ecosur.mx >.

ESTUDIOS DEMOGRÁFICOS Y URBANOS, VOL. 27, NÚM. 3 (81), 2012, 739-787 
Palabras clave: bosques periurbanos, nueva ruralidad, territorio periurbano, Huitepec.

Fecha de recepción: 24 de agosto de 2011.

Fecha de aceptación: 10 de enero de 2012.

Between Forest Conservation and the Growth of the City:

Rural Localities in the Periurban Space of Huitepec

in San Cristóbal de Las Casas, Chiapas, Mexico

Urban growth affects the agricultural and forest areas located in its immediate vicinity, transforming traditional forms of land control and use. Very little information is available on the patterns of this process in medium-sized cities, particularly if the information is provided from the perspective of local actors. This article presents a case study that analyzes the influence of the growth of the city of San Cristóbal de Las Casas, Chiapas, on an adjacent rural area and its effects on forest and farm areas. Although there is an intense process of urbanization, marked by a population increase, the fragmentation of land ownership and the arrival of urban services, some forest areas have been maintained in nature reserves and spaces associated with agricultural and urban uses, forming an agro-forest landscape that provides natural resources and environmental services for the local and urban population, foremost among which is recharging the aquifers. This appears to correspond to a new rurality in which urban and rural socio-environmental processes are spatially integrated and where the forest and agriculture have a different meaning and value for the actors there, which often contradict each other.

Key words: periurban forests, new rurality, periurban territory, Huitepec.

\section{Introducción}

Actualmente más de la mitad de la población mundial vive en centros que se consideran urbanos. Se piensa que el proceso de urbanización se incrementará en las próximas décadas y afectará sobre todo a las ciudades con menos de 500 mil habitantes y a los países en desarrollo (Martine, 2007). En comparación con el porcentaje de la población que alberga, la extensión de la superficie urbana es mínima, pues ocupa entre 3 y $4 \%$ de la superficie global (Grimm et al., 2008; Martine, 2007), aunque las tendencias del crecimiento urbano tienden a ser más dispersas y a abarcar una mayor superficie (Martine, 2007).

Desde el punto de vista ecológico se asume que la urbanización ocasiona fuertes efectos ambientales sobre el medio local adyacente, 
como la contaminación del suelo y el agua, el cambio de uso de suelo y la pérdida de la biodiversidad local (Grimm et al., 2008; Morello et al., 2003; McKinney, 2002). Las secuelas negativas del crecimiento urbano pueden abarcar áreas consideradas de relevancia ambiental y áreas naturales protegidas próximas a las ciudades (Mcdonald et al., 2009); sin embargo también se reconoce que en un contexto de urbanización creciente los espacios naturales vinculados a las ciudades pueden desempeñar un papel fundamental para el mantenimiento de la diversidad natural y los servicios ecosistémicos locales, y que en algunos casos representan los únicos referentes de la experiencia natural para la población urbana (Goddard et al., 2010; Grimm et al., 2008; Wu, 2008; McKinney, 2002). Las áreas arboladas y los bosques que se encuentran dentro o en la periferia de las ciudades proveen una variedad de beneficios a los ecosistemas urbanos, tanto ambientales (regulación del clima, reducción de la contaminación del aire, mitigación del ruido, protección contra escurrimientos de agua, hábitat para especies animales y vegetales, y recarga de acuíferos) como sociales (recreación y educación para la población urbana, abastecimiento de leña y otros recursos) (Wu, 2008; Godefroid y Koedam, 2003).

A escala mundial se ha correlacionado positivamente el crecimiento urbano con la deforestación, ya que las ciudades demandan productos agrícolas provenientes de regiones distantes (DeFries et al., 2010). En la escala local se advierte que el crecimiento urbano afecta significativamente los bosques periurbanos, ya sea por el cambio de uso de suelo o por la modificación de su estructura ocasionada por la extracción de madera, leña y otros recursos (Matlack, 1997; Murray, 1993). En México los escasos trabajos disponibles indican que el efecto del crecimiento urbano sobre los bosques va antecedido en su mayoría por el cambio de uso de suelo con fines agrícolas, lo cual resulta a largo plazo en remanentes forestales fuertemente fragmentados y amenazados por la actividad agrícola, la explotación clandestina de madera, la construcción de viviendas y el desarrollo de la infraestructura urbana (Torres-Lima y Rodríguez-Sánchez, 2008; García-Romero, 2001 y 2002).

Desde el punto de vista social, el crecimiento urbano sobre el medio natural y rural circundante provoca una profunda transformación en las formas de propiedad, gestión y uso de la tierra y de sus recursos, que puede acarrear desde la pérdida de la propiedad de la tierra y el desplazamiento de la población local (Martínez, 2010; Cruz, 1996) hasta el desarrollo de formas de integración socioterritorial de las lógicas urbanas y rurales que inciden en el manejo de los recursos 
forestales. Se ha observado que la gestión comunitaria de los recursos forestales periurbanos que llevan a cabo los ejidatarios y comuneros se debilita ante el surgimiento de identidades "urbanas" donde el valor monetario de la tierra favorece los procesos de apropiación individual y urbanización (Salazar, 2000). Asimismo, la emergencia de nuevas formas de valoración de los recursos naturales como espacios de protección ambiental y conservación de la biodiversidad, permite a los campesinos integrarlas a sus formas de manejo tradicional para garantizar la propiedad y el control de sus recursos forestales (Estrada, 2002).

De tal forma que se puede entender que el crecimiento urbano ocasiona diferentes efectos sobre el medio social y natural circundante, y que éstos dependen de las características propias del proceso de urbanización y también de los territorios rurales previamente existentes. Podemos considerar periurbanos tanto los espacios físicos como los procesos sociales en que se traslapan los ámbitos urbanos y los rurales, los cuales generan territorios complejos donde los actores, las actividades y el uso de los recursos responden a lógicas y normas diferenciadas que adquieren una dinámica propia (Ávila, 2005). Sin embargo buena parte de quienes se refieren a este fenómeno en México se centran en los procesos de urbanización en las grandes ciudades y conglomerados urbanos del centro del país; sobre todo a partir de una perspectiva de tipo geográfico y regional que da cuenta de los aspectos espaciales del crecimiento urbano en su escala regional, pero con pocos ejemplos de la participación local en el proceso. Ante ello vemos la necesidad de reconocer la dinámica particular del crecimiento urbano de las ciudades medias ${ }^{1}$ y su entorno rural, ya que será en éstas donde se concentrará el mayor crecimiento en las próximas décadas, y constituyen un espacio idóneo para analizar las implicaciones sociales y ambientales del crecimiento urbano sobre el medio rural debido a su propia dimensión y su posición intermedia entre las escalas de gobierno nacional y local (Grimm et al., 2008; Wu, 2008; Bellet y Llop, 2002).

Los bosques y las áreas protegidas que se ubican en la periferia de los centros urbanos están sujetos a una dinámica periurbana que es necesario entender y reconocer para hacer posible su permanencia a largo plazo, ampliando las visiones ambientalistas que sólo conciben la

${ }^{1}$ Cada país establece con base en distintas consideraciones el tamaño de una ciudad media, así como el umbral entre lo urbano y lo rural. En México las ciudades medias son aquellas cuyo tamaño va desde 100 mil hasta menos de un millón de habitantes (Conapo, 2005). 
integridad de las áreas naturales en función de su aislamiento, y considerando que incluso en las zonas urbanas pueden desarrollarse procesos de conservación de recursos y servicios ambientales. El objetivo del presente trabajo es analizar qué perspectivas hay para el manejo y la conservación de las áreas forestales que están presentes en las inmediaciones de una ciudad media con fuerte crecimiento, a partir del reconocimiento de las formas locales de propiedad y uso del territorio por los pobladores de los asentamientos rurales previos, y la forma en que responden a la integración al espacio urbano. Se analiza una zona ambiental relevante: el cerro Huitepec, en la ciudad de San Cristóbal de Las Casas, Chiapas.

\section{San Cristóbal de Las Casas y el Huitepec}

La ciudad de San Cristóbal de Las Casas fue fundada en 1529 por Diego de Mazariegos y fungió como capital de la provincia de Las Chiapas. Su delicada ubicación susceptible a inundaciones, su geografía montañosa de difícil acceso, así como su posición subordinada a la ciudad de Guatemala, influyeron en que esta ciudad mantuviera un ritmo de crecimiento lento e incluso en ocasiones regresivo durante la Colonia y el siglo XIX (Aubry, 2008). En la segunda mitad del siglo XX el tamaño de la población aumentó y la ciudad se expandió espacialmente, sobre todo a partir de 1970, cuando se desecó buena parte de la cuenca a fin de evitar las frecuentes inundaciones de la ciudad (García, 2005). Este factor, seguido en los años ochenta por una fuerte inmigración de población indígena proveniente de los municipios aledaños a raíz de los conflictos religiosos y sociales que sufrió la región, así como de una serie de ocupaciones ilegales de algunas zonas de la ciudad después de 1994, propició un fuerte incremento de la superficie urbana y un aumento de la población, la cual supera actualmente 158 mil habitantes (INEGI, 2010). La tasa de crecimiento demográfico de San Cristóbal entre 1990 y 2000 fue de 4.4\%, y con ello se situó en el cuarto lugar entre las ciudades medias del Sistema Urbano Nacional para ese decenio (Conapo, 2005). Actualmente la ciudad alberga a una población multicultural de la cual $30 \%$ pertenece a grupos indígenas de la región (predominantemente tsotsiles), así como numerosos habitantes originarios de otros estados del país y del extranjero. La ciudad de San Cristóbal, que constituye el centro urbano del municipio del mismo nombre, concentra $85 \%$ de la población municipal, y el 
MAPA 1

Zona urbana y localidades rurales del municipio de San Cristóbal de Las Casas, Chiapas

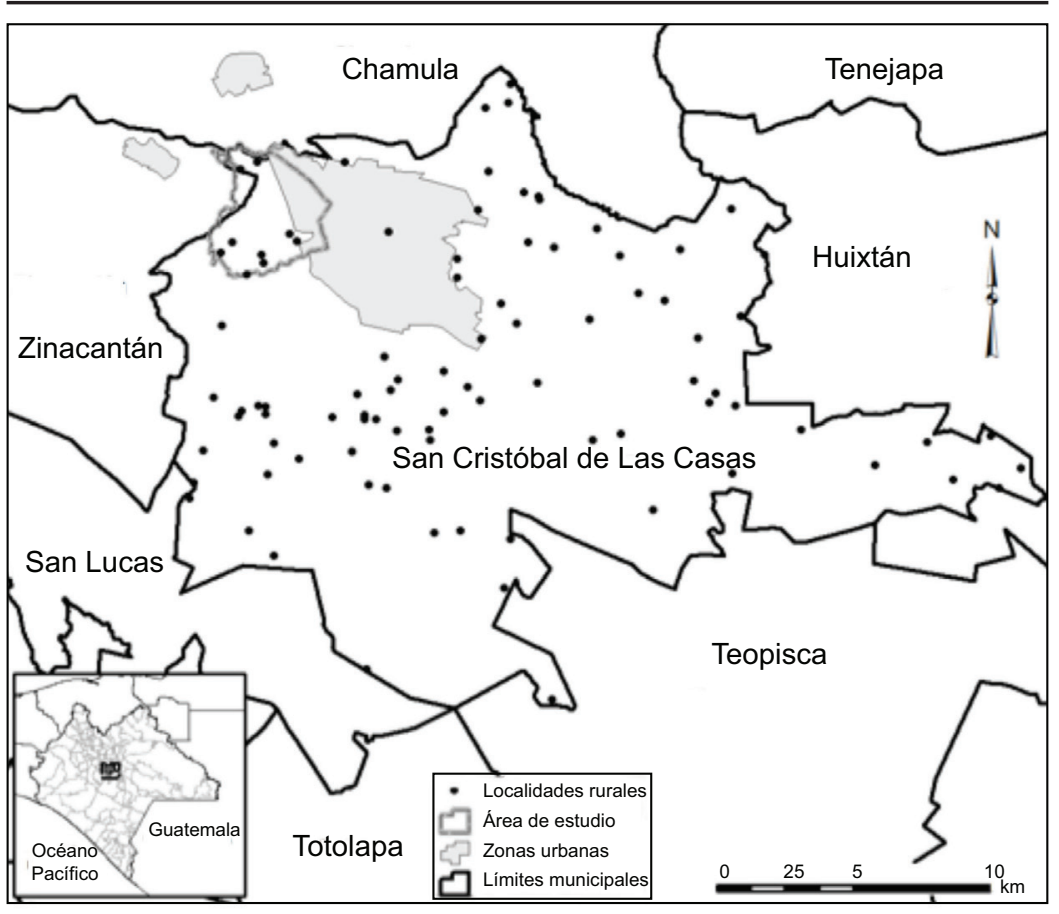

FuENTE: Laboratorio de Análisis de Información Geográfica y Estadística de El Colegio de la Frontera Sur (LAIGE-Ecosur).

$15 \%$ restante habita en 96 localidades rurales dispersas dentro de sus límites (mapa 1). Es a su vez el centro rector de la región Altos de Chiapas, que agrupa 18 municipios cuya población es mayoritariamente indígena.

Fisiográficamente la ciudad se asienta sobre un polje o cuenca endorreica situada a una altitud de 2200 metros y rodeada por áreas montañosas que en sus puntos más altos superan los 2700 metros (García, 2005; Mera, 1984). En sus valles existían zonas inundables y humedales de montaña, y los cerros que la rodean forman parte de un macizo forestal donde se presentan bosques mesófilos de montaña, además de bosques de encino y asociaciones con pino, que son de reconocida importancia estratégica para la conservación de las aves, y 
según la Comisión Nacional para el Conocimiento y Uso de la Biodiversidad (Conabio) es una Región Terrestre Prioritaria (Arriaga et al., 2000; Vidal et al., 1999).

En la intersección de los municipios de San Cristóbal, Chamula y Zinacantán se localiza el Huitepec, un volcán inactivo que se ubica en los bordes de la cuenca a escasos $6 \mathrm{~km}$ del centro de la ciudad y cuya mayor altitud alcanza 2700 metros. Alberga un reducto de bosque mesófilo además de bosques de encino que son un refugio para numerosas especies animales y vegetales de la región, pero su permanencia está amenazada por la agricultura, por la sobreexplotación de sus recursos y por el crecimiento urbano (Henríquez y Rangel, 2009; Naranjo y Espinoza, 2001; Ramírez et al., 1998). En esa zona se estableció la primera reserva natural de tipo privado en México, denominada Cerro de Huitepec (Pronatura, 1987), y ha sido objeto de otros esquemas de protección del gobierno del estado y de la sociedad, que describiremos más adelante.

\section{Nueva ruralidad, estudios periurbanos y conservación de bosques}

Las profundas transformaciones que han ocasionado la globalización y la urbanización sobre las zonas rurales han dado lugar a la formación de nuevos espacios geográficos y al desarrollo de procesos sociales, en los cuales es difícil distinguir los elementos tradicionalmente asociados al medio rural o al urbano. Aunque son numerosos los conceptos que hacen referencia a estos procesos y espacios (C. de Grammont, 2010; Ávila, 2009; Ramírez, 2005),, ${ }^{2}$ varios autores convergen en el término "nueva ruralidad", con el cual aluden a las nuevas condiciones del medio rural ante el desdibujamiento de sus límites y el surgimiento de nuevas conexiones con el ámbito urbano (C. de Grammont, 2010; Gorenstein et al., 2007). Pero también se afirma que la nueva ruralidad constituye un concepto genérico que requiere una mayor precisión teórica y conceptual en estudios concretos (C. de Grammont, 2010; Ruiz y Delgado, 2008).

Para la presente investigación se abordan la conservación y el manejo de áreas forestales dentro de un entorno urbano como un caso

${ }^{2}$ Dependiendo de la disciplina desde la que se analiza, de la postura teórica que se asume y del fenómeno que se describe, podemos encontrar términos como desagrarización, pluriactividad, multifuncionalidad, rusticidad, rurbalidad, periurbanización, conurbación, suburbanización, gentrificación, urbanización periférica, borde, por citar algunos, los cuales no son sinónimos, pues abordan diferentes aspectos de la hibridación de lo rural con lo urbano. 
que refleja esa nueva ruralidad, dada la relevancia que cobra la presencia de la ciudad para el manejo del bosque, y por lo tanto se hace necesario trascender las nociones que normalmente se consideran en la investigación forestal y de conservación de la biodiversidad. La mayoría de las áreas forestales de México se encuentran bajo formas de propiedad comunitaria y forman parte de territorios indígenas, de manera que en su estudio se incluye el análisis de las formas colectivas de apropiación y control de los recursos que son determinantes para la permanencia de los bosques (Merino y Barton, 2004). Sin embargo en el contexto urbano las estructuras sociales de tenencia y manejo de los bosques se transforman drásticamente por la intervención de una multiplicidad de actores, la pugna por la propiedad, y los diferentes usos que se hacen de la tierra (Torres-Lima y Rodríguez-Sánchez, 2008; Salazar, 2000). De igual forma, las áreas protegidas en un entorno urbano enfrentan distintas amenazas y oportunidades que aquellas áreas situadas en espacios naturales alejados de los centros urbanos y más relacionados con las localidades rurales (Macdonald, 2009).

La nueva ruralidad puede adoptar diferentes acepciones y enfoques que han sido analizados y descritos por autores como C. de Grammont (2010), Ruiz y Delgado (2008), Gorenstein et al. (2007) y Ramírez (2005), quienes coinciden en al menos tres enfoques generales: el sociológico, que analiza los cambios y procesos sociales que ocurren en el medio rural y en menor medida en el urbano; el geográfico, que privilegia el análisis espacial de las interacciones urbano-rurales, sobre todo a partir del crecimiento urbano sobre su periferia; y el económico-normativo, que enfatiza la utilidad de la emergencia de conexiones urbano-rurales para un desarrollo rural territorial. Entre estos tres enfoques hay cruces y conexiones que pueden observarse en el uso de conceptos como "periurbano", que deriva de un enfoque espacial y urbano, ${ }^{3}$ pero que aborda cada vez más el análisis de los procesos sociales que ocurren en estos espacios como consecuencia del crecimiento urbano (Ruiz y Delgado, 2008).

Los estudios periurbanos han abordado temas diversos, como los cambios en el uso de suelo y el consumo de espacio, el cambio social, el régimen de propiedad, la agricultura periurbana, y los procesos de patrimonio territorial y preservación identitaria (Ávila, 2009). Pode-

${ }^{3}$ El modelo centro-periferia de Von Thünen considera un esquema ideal donde la ciudad está rodeada por anillos concéntricos cuya función la determinan la distancia y los requerimientos del centro urbano (Ruiz y Delgado, 2008). 
mos encontrar este concepto en una vasta literatura que incluye la ecología urbana, los estudios agrarios, los fenómenos sociales de la urbanización y la forestería urbana. Para ecólogos como Morello et al. (2003) el concepto de "periurbano" se equipara con el de "huella del paisaje urbano"; que proponen para referirse a las apropiaciones y cambios permanentes en un territorio contiguo a la ciudad y que identifican como una interfase en la cual decrecen los servicios provistos por el centro urbano mientras aumentan los servicios ecológicos al alejarse de la ciudad. Por su parte Banzo (2005) considera que si bien la condición de periurbano corresponde a un espacio geográfico situado alrededor de las ciudades que se caracteriza por su discontinuidad, el fenómeno de periurbanización se debe entender como propio de un territorio en el que emerge una forma de vida vinculada a ese espacio.

Aunque la expresión territorial más clara del proceso de periurbanización es la conformación de coronas o espacios periféricos concéntricos en los grandes conglomerados urbanos (Ávila, 2009; Ruiz y Delgado, 2008), si atendemos a la definición de espacio contiguo, y aun de forma de vida, el término puede aplicarse a cualquier urbe. Las ciudades pequeñas y medianas también poseen espacios periurbanos complejos y diversos, aunque en magnitud menor comparada con la de las grandes ciudades; muchas de las transformaciones descritas para áreas periurbanas de grandes ciudades en América Latina tienen su contraparte en ciudades pequeñas o medianas (véase el anexo). Consideramos por tanto que la noción de periurbano es aplicable al estudio de una ciudad media como San Cristóbal, y particularmente para analizar la permanencia de áreas de bosque, ya que alude al carácter espacial del lugar (periférico, contiguo o adyacente a la ciudad), forma parte de un lenguaje común con los estudios de ecología urbana del paisaje, la agricultura y la forestería periurbanas, y coincide con los procesos sociales descritos en el periurbano de grandes urbes.

\section{Métodos}

Variables de análisis en el contexto periurbano

Para el estudio del manejo y la conservación de los recursos forestales es necesario remitirnos a las formas de apropiación de éstos por las sociedades que los poseen. Aunque el término "apropiación" suele 
utilizarse en el sentido de "propiedad", en realidad es una noción más amplia que puede incluir varios conceptos que hacen referencia a elementos abstractos (la cultura, las reglas, las normas y los símbolos que intervienen en la apropiación de los recursos y el espacio) y concretos (las prácticas y usos con relación al recurso) (Godelier, 1984; Weber y Reverte, 2006). La apropiación de un recurso remite necesariamente al espacio o territorio que lo contiene, de manera que en el análisis de los recursos forestales es necesario identificar tanto las cuestiones relacionadas con la regulación colectiva y las normas de uso y acceso a la tierra, como con las prácticas de uso y manejo del recurso (Cortina, 2007; Márquez, 2005; Merino y Barton, 2004; Estrada, 2002).

En las zonas periurbanas las áreas forestales se encuentran estrechamente relacionadas con áreas de uso agrícola y urbano, y mayormente se presentan formas de propiedad individual en las que participan diferentes actores sociales. La presente investigación se propone analizar las variables de propiedad y uso de la tierra y de los recursos forestales del Huitepec como elementos concretos de la apropiación, así como la normatividad o las reglas locales asociadas a los mismos como elementos abstractos (Estrada, 2002; Velázquez, 1997; Márquez, 2005). Para evidenciar la condición periurbana y neorrural que pensamos que existe en el Huitepec es necesario atender al tipo y a la emergencia de los actores sociales que están presentes en el espacio, así como a las transformaciones que han ocurrido a lo largo del tiempo en su relación histórica con el centro urbano.

\section{Delimitación de la zona y localidades de estudio}

Se definió como zona de estudio un área de aproximadamente 1400 hectáreas que incluye las laderas del Huitepec orientadas a la ciudad y que administrativamente pertenecen al municipio de San Cristóbal de Las Casas (mapa 2). El área está delimitada por la carretera a Chamula, la vieja carretera a Tuxtla, y el Periférico, que hasta hace poco representaba el límite externo de la ciudad. De acuerdo con la carta urbana vigente le corresponden usos habitacionales de muy baja densidad y de conservación ecológica; además incluye dos zonas de reserva natural.

Esta área de estudio constituye un fragmento del periurbano de la ciudad en donde ocurre la transición entre los servicios urbanos y los ambientales (Morello et al., 2008) y donde se dividen la zona urba- 
MAPA 2

\section{Localización de la zona de estudio}

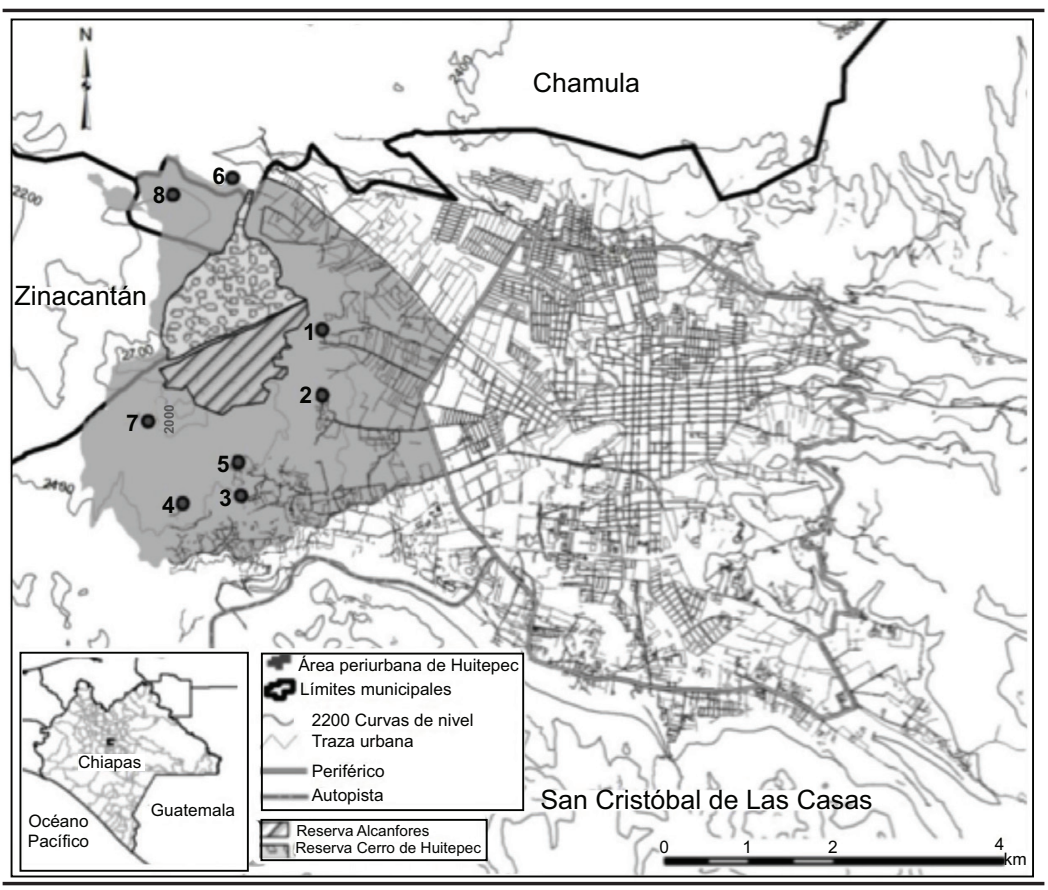

NOTA: Indica la traza urbana de San Cristóbal, las áreas de reserva ecológica y las localidades rurales: 1. Alcanfores, 2. Vistahermosa, 3. Santa Anita, 4. Las Palmas, 5. Ocotal I, 6. Selva Natividad II, 7. Ocotal II, 8. Selva Natividad I.

FuenTE: LAIGE-Ecosur. Polígonos de reservas proporcionados por Pronatura-Sur.

na y la rural, aunque su delimitación precisa varía según las fuentes y criterios que se utilizan para diferenciarlas (áreas geoestadísticas del INEGI, Carta Urbana Municipal, delimitación de LAIGE de Ecosur). En la parte adyacente a la ciudad y las vías de acceso se ubican múltiples colonias, fraccionamientos, propiedades, escuelas, comercios, industrias y servicios diversos que claramente forman parte del área urbana. Arriba de éstas podemos encontrar ocho localidades rurales cuya presencia en la zona se remonta al menos a un siglo atrás; si bien pertenecen al municipio, no forman parte del área urbana a pesar de su cercanía. Finalmente están las áreas de reserva forestal en la parte alta. En este escrito nos centraremos en el análisis de la perspectiva de los pobladores de esas ocho localidades rurales sobre los cambios en su 
espacio ante el crecimiento urbano, así como en las áreas de reserva; aunque se reconoce la relevancia de los espacios y actores de origen urbano en la definición del paisaje ecológico y el entorno social del Huitepec y San Cristóbal, ${ }^{4}$ éstos no se abordan en el presente documento, pero habrá algunas referencias a ellos.

\section{Herramientas}

Se aplicaron entrevistas abiertas a 15 informantes clave para conocer la historia de la propiedad y el uso del suelo en la zona; tal información se complementó con la revisión de censos y literatura histórica de la ciudad, así como con la localización en el Archivo Municipal de San Cristóbal de los documentos a los que se refirieron las fuentes secundarias. Se llevaron a cabo 83 entrevistas estructuradas en las ocho rancherías del Huitepec, lo que equivale a $15.8 \%$ del total de las viviendas asentadas en la zona de estudio y a más de $10 \%$ en cada ranchería (cuadro 1). Se identificaron las características de la unidad familiar, las formas de propiedad y uso de la tierra, y se obtuvo información relativa al uso de los recursos forestales. Se caracterizó el uso actual del suelo de la franja periurbana utilizando una imagen SPOT de 2010 con una resolución de 2.5 metros, a la cual se aplicó una clasificación automática en el programa ArcView que fue revisada y complementada con la información de campo que se reunió en los recorridos y transectos en la zona de estudio.

\section{Antecedentes históricos del uso y propiedad de la tierra en el Huitepec: el bosque como reserva extractiva y frontera agrícola}

Durante la Colonia y el siglo XIX se establecieron diversos ranchos y haciendas, también llamadas "labores", en los alrededores del valle de San Cristóbal; se producía trigo, harina, pan, frutales y otros productos junto con la cría de caballos (mapa 3) (Pedrero, 1987 y 1984). Las haciendas tenían un doble carácter económico: durante los periodos de expansión del mercado cumplían una función predominantemen-

${ }^{4}$ Por ejemplo la presencia de la embotelladora que produce un conocido refresco de cola, la cual extrae agua del Huitepec gracias a una concesión de la Comisión Nacional del Agua. Su presencia es sumamente cuestionada por los actores locales, que la ven como un factor de deterioro ambiental. 


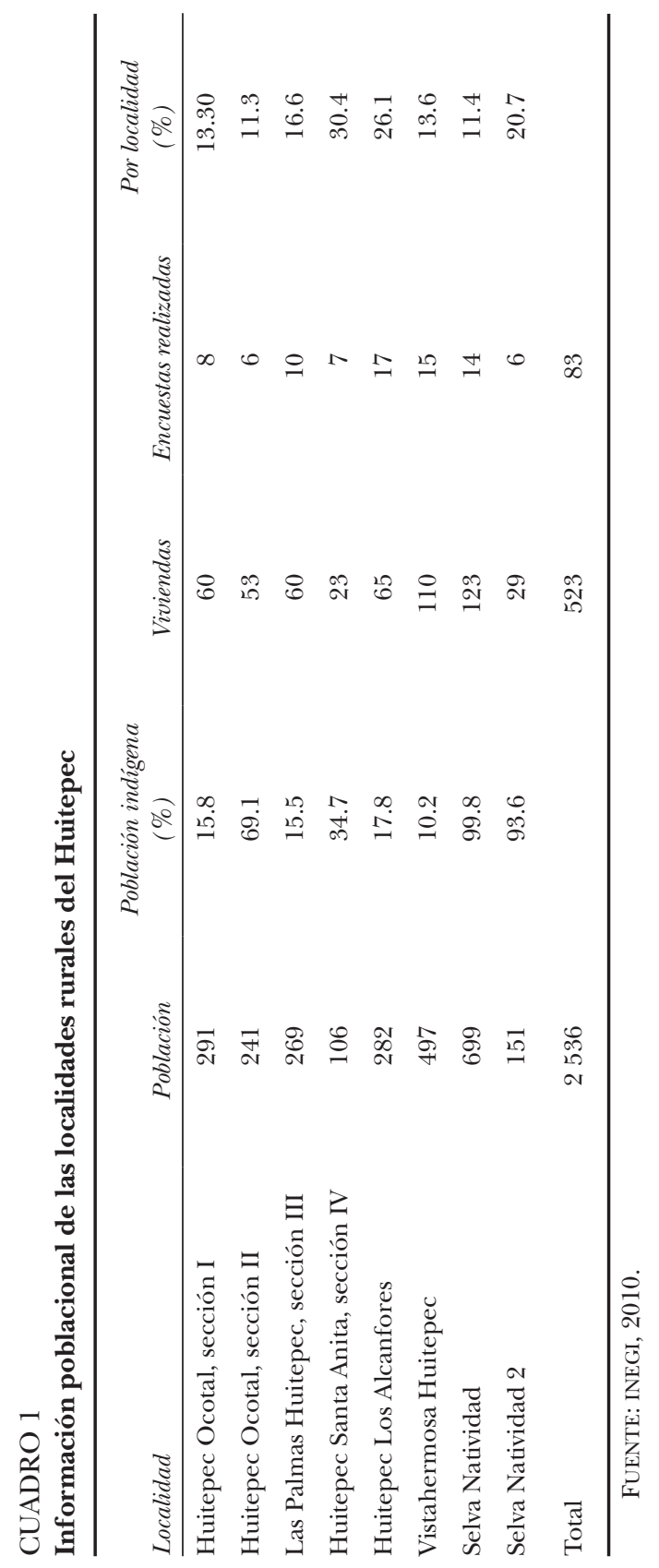




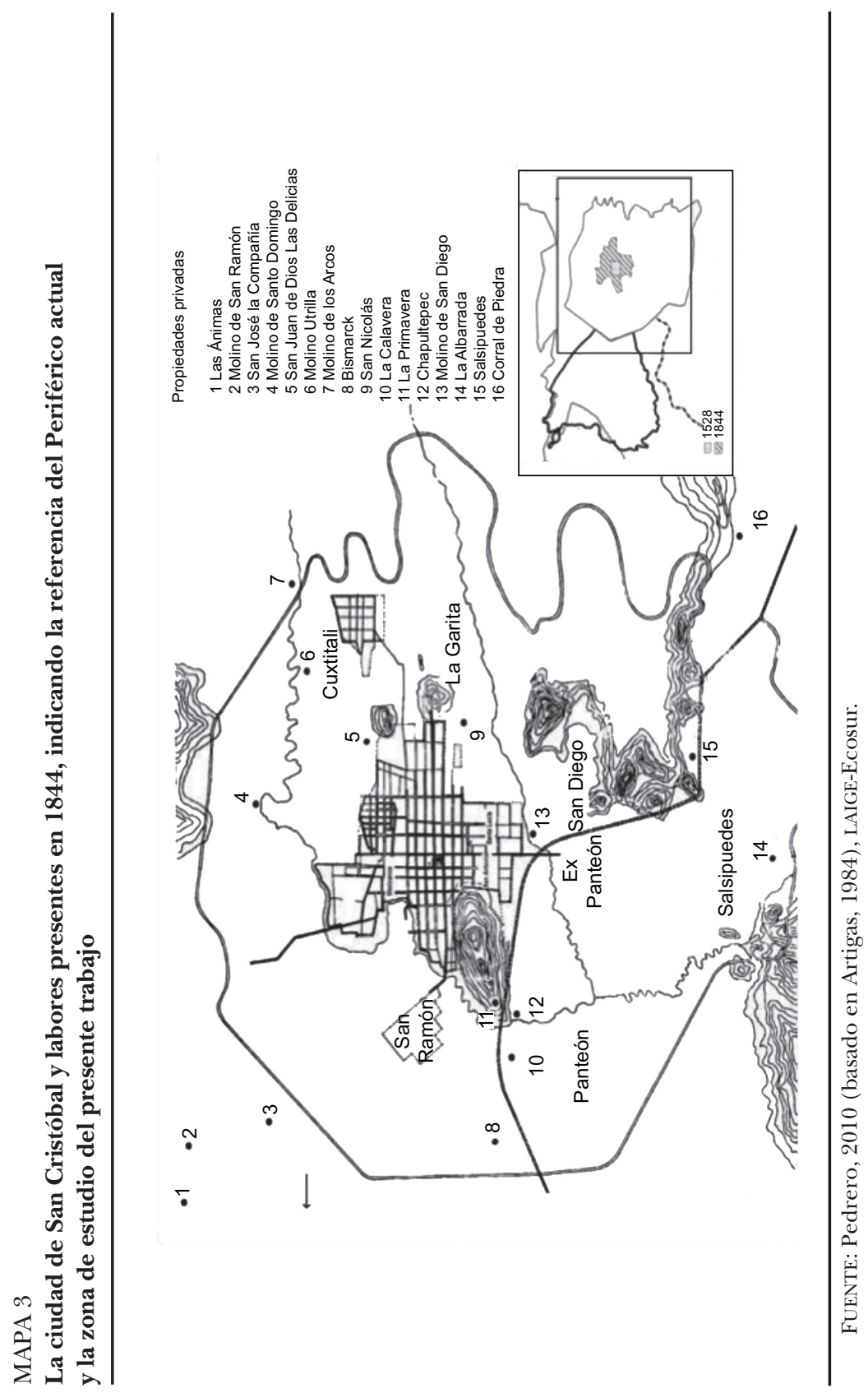


te mercantil, y en periodos de contracción eran una unidad autosuficiente; para ello debían contar con varias clases de tierra (agricultura, pastoreo y bosques), instrumentos de trabajo y mano de obra estable integrada por peones que provenían de los pueblos cercanos (Pedrero, 1987 y 1984). El Huitepec constituía uno de los límites del parteaguas que divide el valle de San Cristóbal de los pueblos indígenas cercanos de Chamula, Zinacantán e incluso de San Felipe Ecatepec, que para ese entonces era un municipio independiente. A principios del siglo XX se hallaban en sus faldas por lo menos cuatro labores de propiedad privada de familias de San Cristóbal (Esquipulas, Las Ánimas, San José la Compañía y Molino de San Ramón), que abarcaban áreas forestales que seguramente se transformaron en áreas agrícolas. Otras zonas del Huitepec, cuya ubicación no es clara actualmente, pertenecían al Ejido de San Cristóbal, el cual representaba un territorio de reserva para el crecimiento de la ciudad y para la provisión de servicios a los pueblos en la época colonial. ${ }^{5}$

A finales del siglo XIX tuvo lugar en México el proceso de desamortización, que afectó a los terrenos nacionales, a los baldíos, a las grandes propiedades religiosas y a las tierras ejidales. Su propósito fue impulsar la creación de pequeñas y medianas propiedades privadas como mecanismo para incorporar tierras "ociosas" a la producción (Pedrero, 2010). En San Cristóbal este proceso comenzó en 1878 y terminó en 1910. Aunque su meta era dotar de tierras productivas a las familias pobres que las solicitaran para laborar, el proceso generó acaparamiento de la tierra, pues casi la mitad del Ejido quedó en manos de 14 familias pertenecientes a la clase alta de San Cristóbal (Pedrero, 2010). Por ejemplo, la labor de Las Ánimas en Huitepec poseía 42 hectáreas hacia 1871 , pero a partir del denuncio de baldíos se hizo de una superficie de 274 hectáreas que se le titularon en 1893 (Pedrero, 1984).

Otras zonas del Huitepec que eran parte del Ejido de San Cristóbal también fueron objeto de reparto, como consta en diversas solicitudes disponibles en el archivo municipal en que algunas familias pidieron terrenos en aquel lugar a finales del siglo XIX y principios del XX (Pedrero, 2010). Excede los propósitos de este escrito precisar la extensión, la ubicación y el número de beneficiarios del reparto del

${ }^{5}$ No corresponde al ejido posrevolucionario, sino al de la época colonial, el cual se consideraba terreno de reserva de crecimiento de los pueblos indios en donde "el agricultor podía descargar sus cosechas, instalar sus colmenares o bien usarlo como sitio de esparcimiento", pero no se podía utilizar de forma particular (véase Pedrero, 2010: 215). 
Ejido en la zona del Huitepec. Algunos datos extraídos de Pedrero (2010) indican que para 1899 se habían repartido 83 terrenos "en la zona oriente y el Huitepec", que las superficies repartidas iban desde $600 \mathrm{~m}^{2}$ hasta 15 ha, y que la mayoría de los solicitantes de tierra en el lugar pertenecían a familias de origen indígena.

En los censos de población de principios de siglo, de 1900 y de 1910, se registra la presencia del "Rancho El Huitepec" con 600 y 700 habitantes respectivamente. Cabe suponer que muchos de ellos fueron beneficiarios del reparto del ejido, aunque probablemente habitaron en ese lugar desde tiempo atrás, pues era común que se solicitaran porciones de tierra que ya se habían trabajado previamente. Además, otros pobladores habían laborado en las fincas ahí presentes, como lo indican los testimonios de algunos de los actuales habitantes cuyos abuelos compraron a los grandes propietarios los terrenos que cuidaban y se hicieron así de una propiedad en el lugar.

De acuerdo con lo anterior, para la primera mitad del siglo pasado la propiedad de la tierra en el Huitepec era ya predominantemente privada, y se podían distinguir dos tipos de actores sociales: por un lado los numerosos propietarios indígenas y mestizos que ocupaban los terrenos de superficies variables que habían adquirido por adjudicación o compra, y por otro los grandes propietarios de antiguas labores (al norte de la zona de estudio). Una porción de bosque remanente del Ejido colonial continuó siendo utilizada de forma colectiva por los pobladores del Huitepec, pero sin que se asignara formalmente como tal. El uso del suelo era agrícola en las partes bajas o accesibles, con producción de maíz y pasto para la cría de ganado (vacas, caballos, cabras), mientras los bosques situados en las partes altas eran de uso forestal, en particular la leña que extraían los pobladores para venderla en la ciudad, así como para su uso doméstico.

\section{Transformaciones periurbanas en el Huitepec: el bosque como proveedor de servicios ambientales}

La situación prevaleciente en términos de propiedad a principios de siglo representó tres procesos relativamente divergentes de apropiación territorial en el entorno urbano: la conformación de rancherías a partir de la población asentada ahí con pequeñas propiedades, la permanencia del Ejido como un área de usufructo forestal colectivo por parte de esas rancherías, y las transformaciones en las grandes 
fincas privadas. Abordaremos a continuación las dos primeras y retomaremos un caso del tercer tipo dada su relevancia para la presencia del bosque.

\section{Las localidades rurales ante el crecimiento urbano}

Los cambios más relevantes en la organización socioespacial del Huitepec pueden observarse en dos momentos: en primera instancia la formación de varias rancherías a partir de una sola localidad, lo que permitió a una creciente población local incrementar la presencia de servicios urbanos; en segunda instancia la llegada de pobladores de origen urbano, que se consolidó a partir del año 2000 y propició el desarrollo de un mercado de tierras. Ambos momentos representaron una fragmentación del territorio, el cambio en las actividades productivas y el surgimiento de nuevos actores y conflictos.

\section{El crecimiento de localidades rurales}

Después del censo de 1910, donde se registró que la ranchería El Huitepec tenía más de 700 habitantes, en las siguientes décadas no hubo información consistente hasta 1970, cuando se asienta la presencia de dos localidades diferentes: Huitepec Ocotal y Alcanfores Huitepec, con una población total de 870 habitantes. En los siguientes 40 años el número de localidades se incrementó hasta formar ocho, que en conjunto concentraban una población superior a 2500 habitantes para 2010 (esquema 1 y gráfica 1 ). ${ }^{6}$

El surgimiento de estas nuevas localidades rurales o rancherías se ha dado a partir del incremento de la población y la consecuente necesidad de servicios (escuela y caminos, entre otros) de algún grupo que considera carecer de ellos. Con excepción de Selva Natividad, ${ }^{7}$ la formación de rancherías independientes no ha implicado el desplazamiento de la población ni la ocupación de nuevas áreas, sino que constituye una forma de organización y segmentación socioespacial

${ }^{6}$ Cabe mencionar que las áreas geoestadísticas que maneja el INEGI incluyen dentro de la zona urbana de San Cristóbal buena parte de lo que localmente se considera "ranchería" en Alcanfores.

${ }^{7}$ Formada a partir de que algunas familias de origen chamula que salieron de sus comunidades por motivos religiosos y compraron un terreno a uno de los grandes propietarios en 1985. 


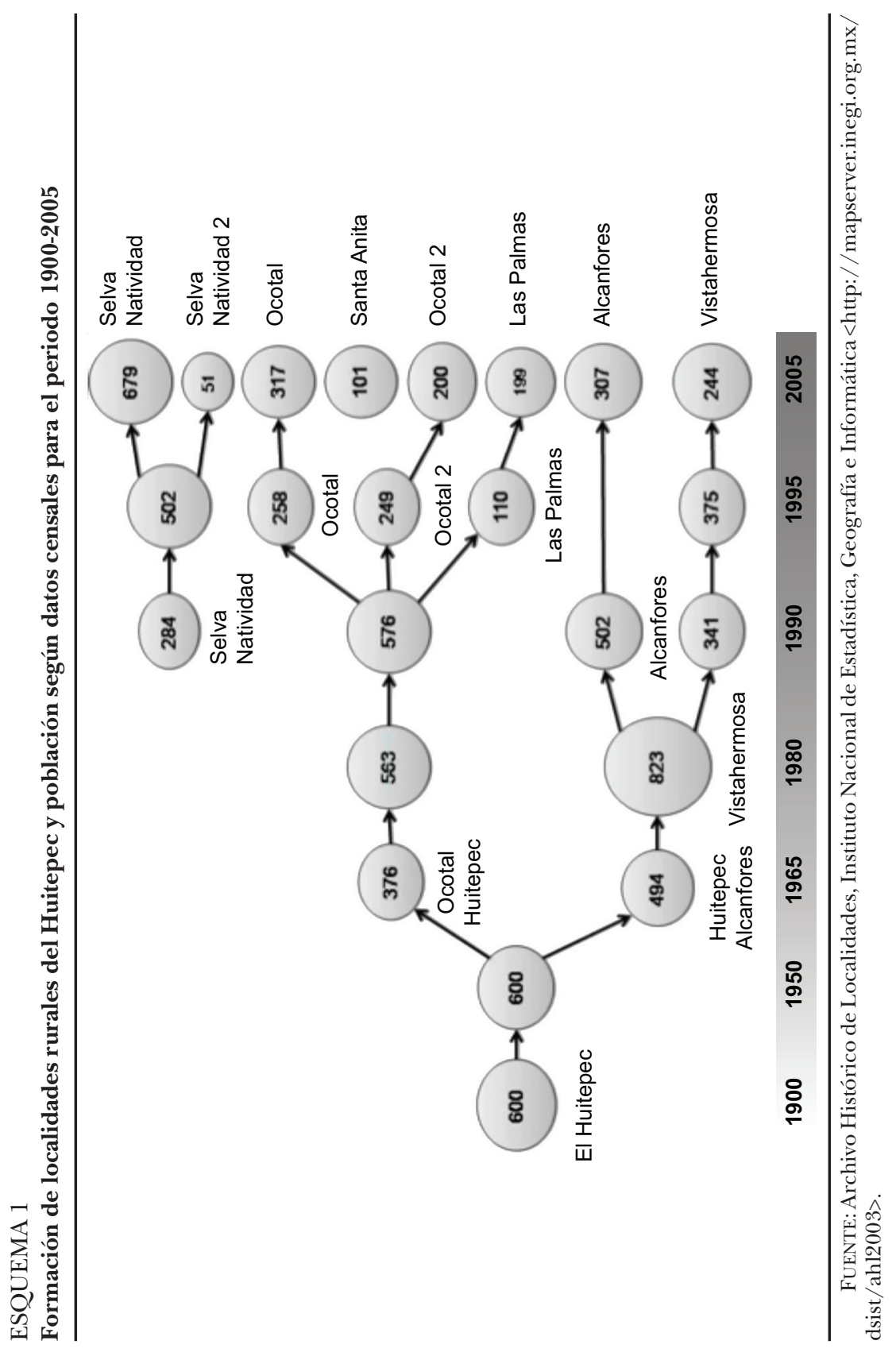




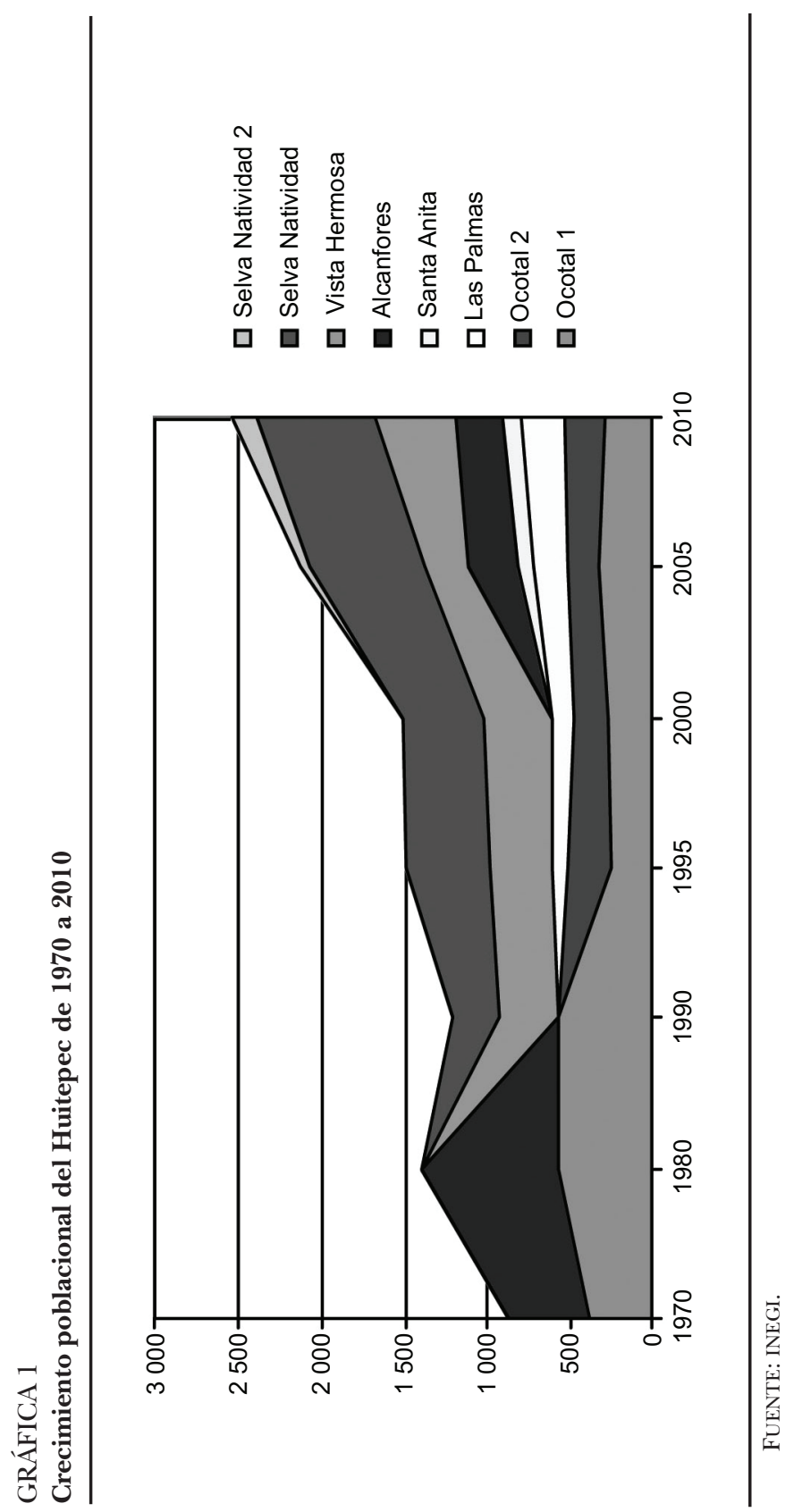


que proporciona a los pobladores una mayor capacidad de gestión de servicios ante el municipio y una cierta autonomía respecto al uso de su espacio, al igual que ocurre, según reporta Torres-Mazuera (2009), en un municipio del Estado de México. Cada ranchería nombra un representante que el gobierno municipal reconoce como agente rural, ${ }^{8}$ y los miembros de dicha ranchería se organizan localmente en comités para la construcción y mantenimiento de caminos, el apoyo de actividades escolares, la limpieza de manantiales y otras tareas que consideren necesarias. En cada ranchería se establecen reglas para participar en esos comités y desempeñar esos cargos, y se realizan asambleas para discutir los asuntos internos y tomar decisiones; debido al origen indígena de las localidades, las reglas de participación reflejan las estructuras tradicionales de usos y costumbres de la región. ${ }^{9}$ El siguiente testimonio refleja el primer proceso de separación de rancherías y las características que definen tal proceso.

En 1962 era un solo Huitepec que pertenecía hasta Alcanfores... pero en 1963 se hace la división... Resulta que los niños estaban muy lejos para llegar a la escuela... entonces tuvimos que hacer la división... Hacen la escuela y se empiezan a venir los niños para acá. Pero no había carretera. ¿Qué hizo la gente? Empiezan a trabajar con picos, palas y empiezan a hacer la brecha de la carretera, porque en aquellos tiempos los presidentes no ayudaban... Resulta que en los próximos años nombran ya aquí al Agente Auxiliar que... es el que ya ve la comunidad... y empiezan las ayudas. Al tener el agente ya dan el sello, ya se puede gestionar, lleva usted el documento, va a la Presidencia y ya le dan el tractor o algo, pero ya lo apoyan... Entonces en 1973 rompen el cruce del camino, que ya fue gestión del agente. Entonces como fue creciendo la población vienen las [otras] divisiones [informante clave, Ocotal 1].

En este testimonio se advierte que los pobladores de las localidades han desempeñado un papel significativo en la provisión de los servicios urbanos con que ahora cuentan (escuelas preescolar y primaria, energía eléctrica en las viviendas, vías de acceso que funcionan todo el año,

8 El Ayuntamiento tiene la facultad de designar agencias y subagencias auxiliares rurales en las que se nombra a un agente que representa al gobierno municipal en la localidad, o a la localidad ante el gobierno municipal. Su duración en el cargo es de un año (Reglamento de las Agencias Auxiliares Rurales Municipales de San Cristóbal de las Casas).

${ }^{9}$ Por ejemplo en la localidad Selva Natividad el cargo más alto es el de agente rural, al cual sólo se accede después de haber ocupado una serie de cargos de menor rango. 
alumbrado público, tomas de agua en las viviendas), pues casi todos fueron realizados o gestionados, al menos inicialmente, por los pobladores, quienes los planearon según sus propias necesidades; actualmente ellos mismos se organizan para su mantenimiento. Si bien el trazo de los caminos en la zona se realizó durante un proceso lento y continuo desde décadas atrás, el crecimiento de la red de servicios urbanos ha sido relevante a partir de la división del espacio en varias localidades. Cabe afirmar que los pobladores locales han representado el principal motor para la integración del Huitepec al área urbana de San Cristóbal por medio de sus gestiones y sobre todo de su trabajo para construir caminos y ampliar la red de servicios. Contra lo que afirma Zárate (2008), los pobladores no se han visto afectados pasivamente por el crecimiento urbano, sino que han participado plenamente en el proceso, aun cuando esto haya implicado otros costos, como se verá más adelante.

\section{Llegada de pobladores urbanos al Huitepec}

Los procesos de crecimiento urbano que se presentaron en San Cristóbal a partir de 1970 (mapa 4) favorecieron la llegada de pobladores de origen urbano al Huitepec, situación que se intensificó a partir de 1994 cuando la incertidumbre política del estado propició la venta a bajo costo de numerosos terrenos en la zona, algunos de los cuales fueron fraccionados años más adelante por quienes los adquirieron en mejores condiciones. ${ }^{10}$ Después del año 2000 se ha incrementado notablemente la llegada de pobladores urbanos atraídos por la presencia de servicios, por los recursos naturales y por el precio relativamente bajo del terreno. De acuerdo con las entrevistas que realizamos para esta investigación, actualmente $67.5 \%$ de las familias que habitan en las rancherías son originarias del Huitepec, mientras $32.5 \%$ llegó de fuera, sobre todo de San Cristóbal y Chamula, aunque varias provienen de otros estados del país o del extranjero. El tiempo de residencia de los pobladores de origen externo va de uno a 25 años, y con 10 años en promedio.

El atractivo del lugar como polo de crecimiento urbano favorece un mercado de tierras cada vez más fuerte, y en algunas zonas se está

\footnotetext{
${ }^{10}$ Según un informante, para 1994 se adquirieron terrenos en Alcanfores a 5 pesos el metro cuadrado; para 2009 el precio en esta zona oscilaba alrededor de 2000 pesos por metro cuadrado.
} 


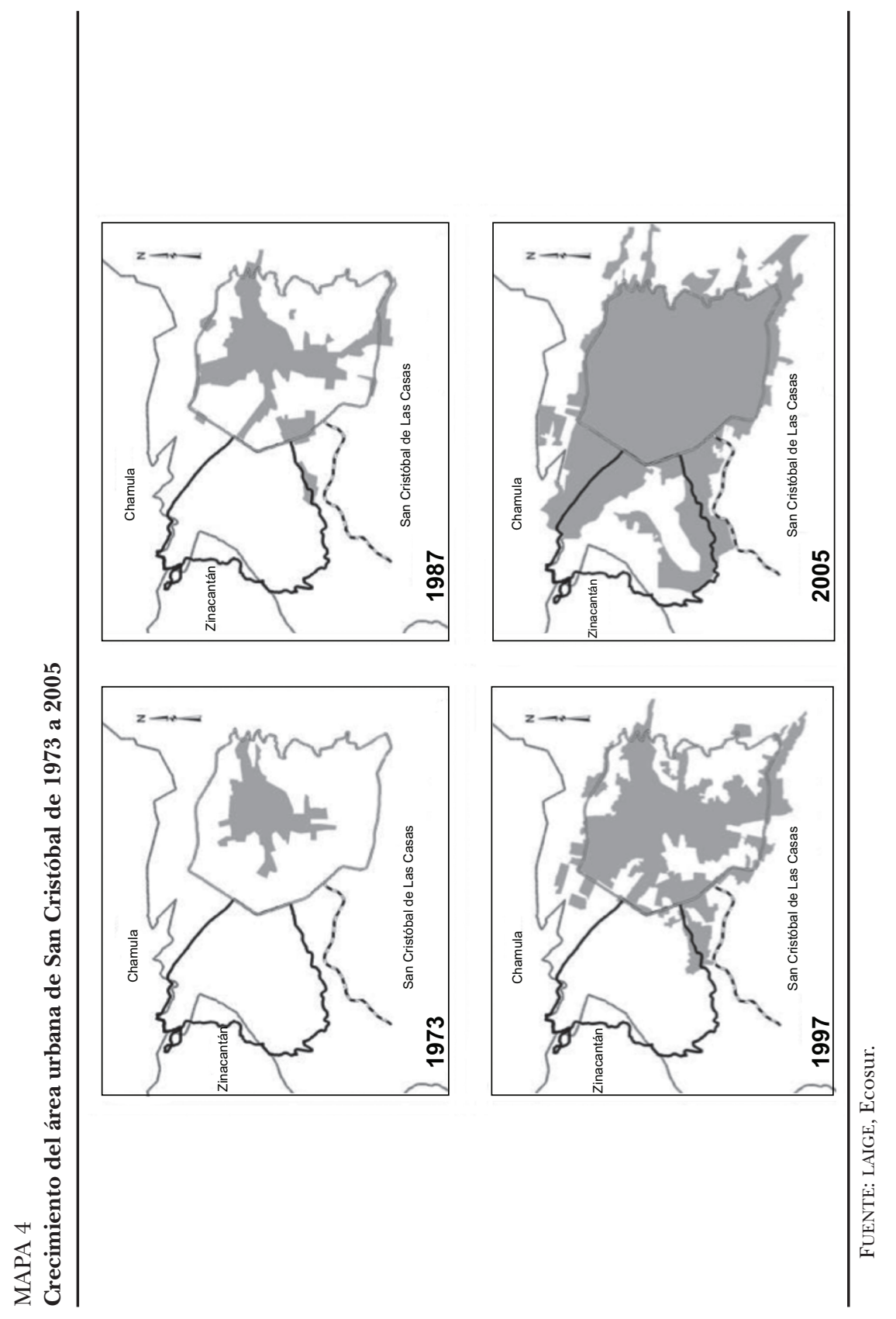


generando una urbanización selectiva de tipo "campestre" cuya principal virtud es la presencia combinada de servicios y áreas verdes, sobre todo en las localidades que cuentan con mayor presencia de servicios y están cerca de la ciudad, como Alcanfores y Vistahermosa. Sin embargo al Huitepec también han llegado indígenas y mestizos de la región debido a que adquirieron pequeños lotes de terreno a bajo costo; el caso más relevante es Selva Natividad, localidad formada en su totalidad por indígenas tsotsiles de Chamula, aunque hay familias de la región dispersas en el resto de las rancherías.

El origen de los pobladores permite hacer una primera distinción entre los actores sociales que actualmente intervienen en la apropiación del espacio y el manejo de los recursos naturales de las rancherías. Por un lado están los pobladores originarios del Huitepec que han habitado allí desde al menos un par de generaciones, quienes se identifican a sí mismos como "nativos", y por otro lado están los pobladores externos que han llegado a vivir en el lugar procedentes de la ciudad de San Cristóbal (a quienes en este escrito denominaremos "pobladores urbanos") y otros pobladores de la región provenientes de distintas localidades de Los Altos, en su mayoría indígenas. El incremento de la población nativa y la llegada de los nuevos pobladores propician el surgimiento de conflictos entre ambos sectores, sobre todo por el acceso al agua, recurso cuya disposición es cada vez menor ante el incremento de los usuarios. Otros conflictos derivan de la participación en la toma de decisiones en las asambleas, el uso de los servicios urbanos y la forma en que coopera y participa cada sector. Los recién llegados tienen que cubrir una cuota de acceso, participar en las actividades de mantenimiento de los caminos y acatar las disposiciones de la asamblea local, integrada en su mayoría por pobladores nativos, que se rigen por usos y costumbres, quienes reivindican lo que consideran su derecho para tomar decisiones sobre diferentes aspectos de la comunidad, así como exigir la contribución de los recién llegados al mantenimiento de los caminos que ellos realizaron. Los siguientes testimonios dan cuenta del conflicto y de la perspectiva de cada sector:

¡Sí, nosotros lo hemos hecho! Y por eso, mire... si usted quiere comprar un terreno allí... van a ir a hablarnos... "mire usted señor, voy a comprar un terreno con fulano de tal, yo quiero ingresarme con ustedes, ¿cuánto va a ser mi ingreso?... ¿y a ese dinero qué le hacen si la carretera ya está?”... Ese dinero que usted va a aportar va servir para la misma carretera, nosotros jamás tocamos un peso del dinero que le pedimos a alguien. Cuando metimos esos postes de luz, los trajimos cargando sobre los hombros, 
éramos como 12, pelados llegaron nuestros hombros. Por eso es que cobramos ese dinero, por motivo de que nosotros cargamos los postes y pagamos a la comisión. Ahora hay carretera, hay luz ¡cualquiera quiere llegar! [informante clave, Vistahermosa].

¡Se sienten dueños de los caminos! [pobladora reciente en Ocotal 1].

Ante el incremento de la población y de los servicios urbanos presentes, la propiedad privada se ha multiplicado en numerosos dueños, pues se han ido fraccionando los terrenos en lotes cada vez más pequeños al heredarse o venderse la tierra. Algunos de los primeros compradores habían adquirido terrenos de más de 10 o 20 hectáreas, pero hoy el tamaño más común de lote es de $300 \mathrm{~m}^{2}$ y sólo unas cuantas familias poseen terrenos que miden más de una hectárea. La propiedad y la compraventa de la tierra se acuerdan mayormente mediante transacciones locales y contratos privados, y sólo algunos propietarios (sobre todo los de origen urbano) poseen escrituras notariadas de sus terrenos. Lo anterior no impide que en los hechos las propiedades se dividan entre los miembros de una familia o que se vendan a terceros, dado que internamente se reconocen sus límites. Sin embargo la propiedad privada que se sustentaba en arreglos internos y relaciones de confianza está cambiando, ya que muchos pobladores están tratando de legalizar sus posesiones, en parte debido a la limitante que este hecho representa para el precio de venta de las mismas.

En términos de uso de suelo se deben resaltar los cambios en las actividades agrícolas y forestales. Si la agricultura era uno de los rasgos característicos del medio rural, sus transformaciones son uno de los aspectos más significativos de la nueva ruralidad. Todavía en la década de los cincuenta esta actividad tenía relevancia en el Huitepec entre la población nativa, ya fuera que se realizara en parcelas propias o en los terrenos que rentaban los grandes propietarios para la producción de maíz y la cría de ganado. Con la reducción del tamaño de los terrenos, la conexión al centro urbano y el incremento de las fuentes de empleo no agrícola, esta actividad sufrió dos cambios relevantes y opuestos: fue abandonada por un amplio sector de la población, y hubo una especialización cada vez mayor de algunas familias que disponían de fuentes de agua para la producción de hortalizas destinadas a los centros urbanos cercanos (Tuxtla, Ocosingo, San Cristóbal). Actualmente la principal fuente de ingresos para los miembros de las familias del Huitepec son los empleos en la zona urbana de San Cristóbal (albañiles, jardineros, mecánicos, músicos, carpinteros, profesionistas o 
comerciantes). La agricultura tiene gran relevancia cultural, dado que en $57.8 \%$ de las viviendas todavía se cultivan algunos productos, pero sólo $32 \%$ recibe ingresos por esta actividad y su aporte a la economía familiar en general es de $17 \%$, el cual es bajo en comparación con $71 \%$ que aporta el empleo urbano y local, y es apenas superior al $11.8 \%$ que aportan los programas de apoyo social gubernamental (Oportunidades y Apoyo a Adultos Mayores).

La actividad agrícola permite introducir una segunda distinción en los actores sociales y la forma en que se relacionan con el espacio del Huitepec. La agricultura comercial se desarrolla sobre todo en las rancherías Ocotal 1, Ocotal 2, Las Palmas y Santa Anita (en la ladera sur), donde $74 \%$ de las familias siembra algún producto y el aporte a la economía familiar alcanza 39\% del ingreso total. Aún siembran pequeñas áreas de maíz de temporal, pero la producción principal corresponde a hortalizas y flores, ambas destinadas al mercado urbano. Los agricultores cuentan con propiedades de mayor tamaño $\left(3800 \mathrm{~m}^{2}\right.$ en promedio) y frecuentemente poseen un segundo terreno. La mayoría de las áreas de cultivo se intercalan con fragmentos forestales que se dejan para obtener abono o proteger los cultivos contra plagas, o al menos se favorece la presencia de árboles frutales y cercos vivos en torno a ellos. Algunos agricultores se han vinculado a un mercado urbano que valora las limpias condiciones de producción de este lugar (agua limpia y uso de abonos naturales), con lo cual obtienen mejores ingresos, pero mediante acuerdos de confianza y verificación interna se comprometen a mantener ciertas condiciones en su producción. Sin embargo la mayoría continúa vendiendo en el mercado convencional valiéndose de intermediarios. Cabe mencionar también que algunos de los pobladores de origen urbano están incursionando en las actividades agrícolas en pequeña escala y cultivan pequeños huertos para consumo propio.

Respecto al uso forestal podemos reconocer que estos recursos aún son relevantes para la población, ya que $81.9 \%$ de las familias utiliza leña, la mayoría diariamente; además $40.7 \%$ obtiene otros recursos, principalmente del suelo para los cultivos, plantas medicinales y hongos comestibles (véase el cuadro 2). La mitad de las familias (50\%) compra su leña, una tercera parte (33\%) la obtiene del terreno propio y $17 \%$ la recolecta de propiedades cercanas que aún mantiene en el bosque, lo cual refleja la escasa disponibilidad del recurso en sus terrenos y las dificultades que enfrentan para abastecerse en las zonas de reserva. La percepción de la población en general es que en las 
rancherías se está acabando el bosque en comparación con épocas pasadas: "Nos va a ir muy mal, viene mucha sequedad acabando los árboles. No tumban uno y resiembran otro. Ya hicieron demasiadas casas, antes todo estaba arbolado" (Ocotal 1).

Más allá de su uso directo, actualmente el bosque se valora por su papel en la captación del agua, recurso que depende exclusivamente de la presencia de manantiales y pozos en la zona, los cuales se manejan de forma individual, familiar o colectiva según su tamaño y localización (cuadro 2). Otras fuentes de agua incluyen la captación de lluvia en forma individual y colectiva, y la compra de pipas. Ya sea que se trate de un pozo en los terrenos propios, de un manantial compartido entre un grupo pequeño de familias o vecinos, o bien de un manantial comunitario o colectivo de múltiples usuarios, las personas involucradas se autoorganizan en sistemas más o menos complejos, según sea el caso, para limpiar el manantial, mantener la red de distribución y celebrar rezos y fiestas en el mes de mayo. El mantenimiento del manantial generalmente implica el cuidado del bosque que lo rodea. En la localidad de Selva Natividad, por ejemplo, las familias han comprado colectivamente los árboles que rodean el manantial, ya que éste se encuentra en una propiedad privada. De tal modo el mantenimiento de las fuentes de agua, vitales para las localidades, implica el establecimiento y la adopción de ciertas reglas que indirectamente inciden en el uso de la tierra y el cuidado del bosque en el Huitepec.

No es clara la existencia de normas específicas que regulen el uso de suelo en los terrenos de propiedad privada en las rancherías. La mayoría de los habitantes considera que no se pueden imponer reglas sobre lo que los propietarios pueden o no hacer en sus terrenos, ya que se trata de propiedad privada; algunos agentes mencionaron que si bien existen ciertos lineamientos para regular el desmonte o el fraccionamiento de los terrenos, no se cuenta con mecanismos de control o sanción específicos, salvo los que puedan generarse a partir de los derechos de uso de los servicios colectivos, tales como los caminos o el abasto de agua.

Ahora bien, hay una normatividad municipal que en teoría es aplicable en la zona, la cual se sintetiza en la Carta Urbana Municipal, donde se indica cuál es el uso de suelo que se ha determinado para este espacio: habitacional rural de baja densidad y de conservación ecológica. Sin embargo en la localidad es evidente la falta de presencia del gobierno municipal, tanto en lo que se refiere a la dotación de servicios como a la regulación del uso de suelo, ambos determinados 


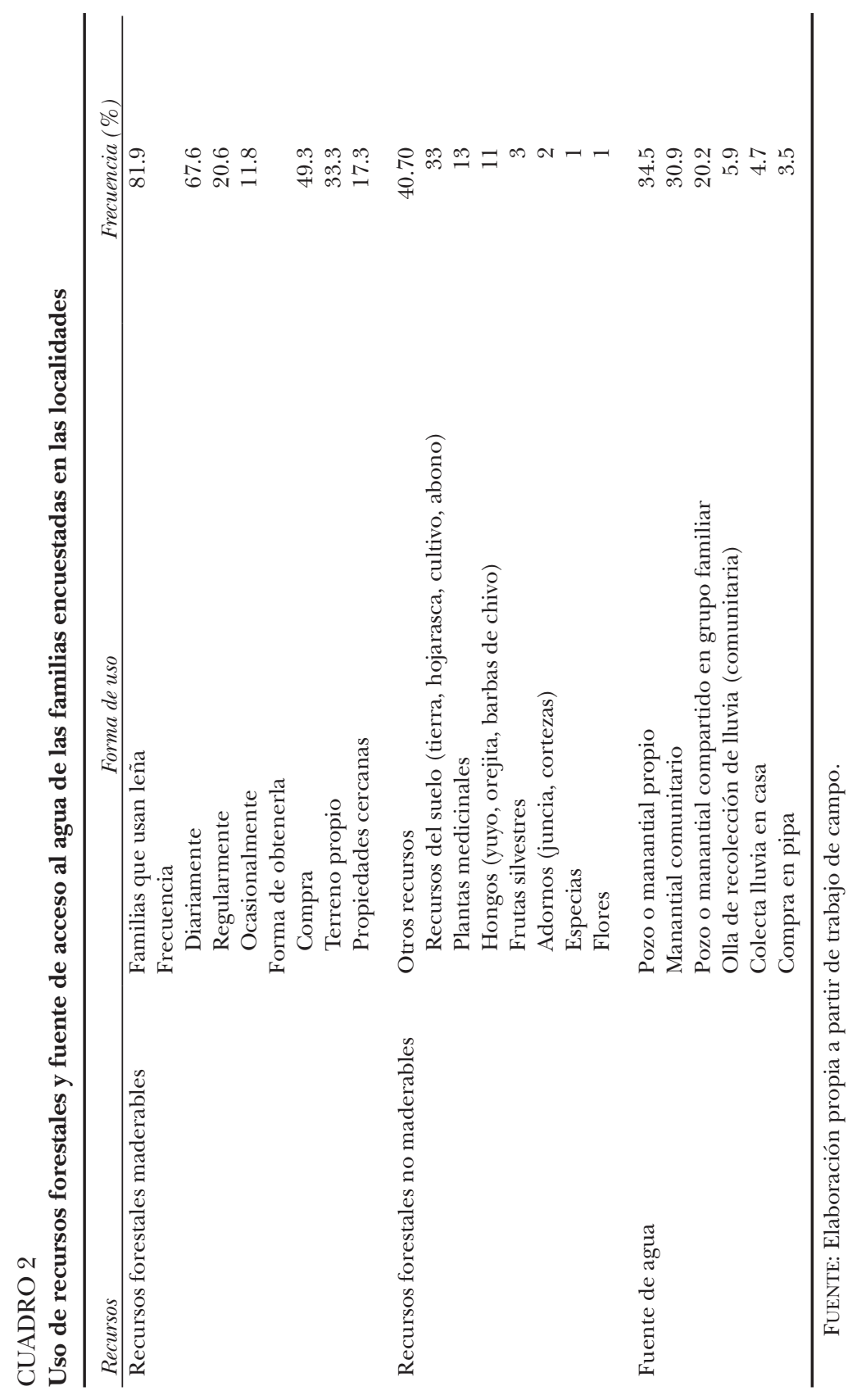


por la población local. En los hechos la figura del agente rural es más una representación de la localidad ante el municipio, que viceversa. Sin embargo existe la posibilidad de recurrir a la reglamentación oficial, que se utiliza según convenga a distintos sectores. Por ejemplo, algunos propietarios han gestionado permisos de cambio de uso de suelo o construcción ante las instancias municipales sin acatar las disposiciones de la asamblea local:

Sí, hay reglas, por ejemplo en el bosque se puede ir tumbando a cada diez árboles cortar uno, pero ve usted que las autoridades son canijas, han dado permiso de que tumben por hectáreas... cuando fue presidente Enoc Hernández... imagínese ¡dio permiso para que talaran dos hectáreas de bosque! Entonces nosotros no podemos sancionar, como son propiedades privadas no podemos entrar, pero las autoridades competentes sí pueden entrar. Pero se hacen de la vista gorda y ahí queda [informante clave Ocotal 1].

Ante la nula existencia de reglas internas y la falta de una efectiva presencia de una regulación municipal para el control del bosque en el terreno de las rancherías, su mantenimiento depende exclusivamente de las decisiones que sobre su espacio tomen los dueños de los terrenos que aún tienen áreas arboladas. Sin embargo, el reducido tamaño de los terrenos que posee la mayoría de los pobladores hace que las áreas de interés para la conservación se trasladen hacia las zonas de reserva o hacia las propiedades privadas que aún tienen bosques, lo cual incrementa la tensión entre los distintos actores de este espacio.

\section{El devenir del Ejido: de reserva extractiva a reserva natural}

En la parte alta del Huitepec, colindante con las rancherías, se encuentra un área de 102 hectáreas que seguramente es un remanente no adjudicado del ejido de la época colonial, ya que aunque los pobladores nativos se refieren a esa zona como el "Ejido" nunca se dotó a la población del Huitepec de este tipo de propiedad después de la Revolución (véase en el mapa 2 la Reserva Alcanfores). ${ }^{11}$ El "Ejido" era utilizado por los pobladores de la ranchería El Huitepec, y después por las rancherías que se formaron a partir de ésta, como una reserva

${ }^{11}$ Según García (2005) y un informante clave, para las autoridades agrarias el área corresponde a Terrenos Nacionales. 
forestal extractiva donde por derecho consuetudinario la población se abastecía de leña, carbón, madera, hongos y otros recursos maderables y no maderables, y donde también se aprovechaban las fuentes de agua. Durante casi todo el siglo pasado el área funcionó de esa manera, pero la presencia de otros actores en la zona y la presión urbana sobre la tierra suscitaron dudas respecto a la situación legal del espacio. A pesar de que se refiere que existían reglas para su uso y cuidado que eran competencia de los pobladores nativos, lo cierto es que no resultaron en un control efectivo de la zona, ya que tanto los pobladores de las rancherías como algunas personas de la ciudad de San Cristóbal ingresaban al "Ejido" a extraer madera, carbón y leña con fines comerciales. Ante el nulo control que ejercían los mecanismos locales y ante la evidente indefinición legal de la propiedad de la tierra surgieron varios interesados en apropiarse de este espacio y de sus recursos: las fuentes de agua para San Felipe y los agricultores locales, y el terreno para la construcción de la ermita de Alcanfores. Finalmente, en 2003, hubo un intento de invasión para su urbanización por habitantes de las localidades vecinas y de otras áreas.

Estos hechos alertaron al resto de los pobladores de las rancherías (tanto nativos como urbanos) y a la comunidad ambientalista de San Cristóbal sobre la relevancia del área y la necesidad de formalizar su función. Como resultado de distintas gestiones de los pobladores locales, los agentes ambientalistas y el gobierno del estado, en el año 2007 fue declarada por el gobierno de Chiapas (Gobierno del Estado de Chiapas, 2007) "Área Natural Protegida Huitepec-Los Alcanfores”; pero la Junta de Buen Gobierno de Oventic ${ }^{12}$ a su vez la declaró Reserva Ecológica Comunitaria Zapatista a solicitud de un grupo de familias de la ranchería de Ocotal 2 simpatizantes de este movimiento, y desde entonces ha sido ocupada por personal de las comunidades zapatistas de la región, que actualmente la resguarda y determina la posibilidad de acceso de otros actores, incluyendo a los pobladores nativos.

La presencia de los elementos de las bases de apoyo (originarios de otros municipios de Los Altos) divide a los pobladores de las localidades del Huitepec en cuanto a su papel real en la protección del sitio, y sobre todo respecto a sus planes a futuro. Muchos no están de acuerdo con la presencia de los zapatistas, ya que se restringió el uso de los recursos a la población local ( $72 \%$ de las familias que antes llegaban al

12 Se refiere a los gobiernos autónomos creados por comunidades ligadas al movimiento zapatista que hizo pública su presencia en Chiapas en 1994. Inicialmente fue un movimiento armado y rápidamente se convirtió en un movimiento social. 
"Ejido" ya no lo hacen); ya no pueden obtener leña o plantas, e incluso señalan que deben realizar a escondidas el mantenimiento de los manantiales de agua (situados dentro de la reserva). Otros más reconocen que en realidad la población local no había sido capaz de regular la extracción y cuidar la zona, pero aun así consideran que los pobladores nativos del Huitepec deben resguardarla, pues el interés de los que hoy la vigilan es apropiarse de ese espacio y no de protegerla; de hecho algunos afirman que los zapatistas están talando los árboles y sembrando dentro de la reserva. Algunas familias están a favor de su presencia y aseguran que desde su llegada se detuvo la tala de árboles. La tensión por este conflicto adquiere en momentos dimensiones alarmantes. De este modo, los zapatistas (población local simpatizante, bases de apoyo regionales, Junta de Buen Gobierno) son los nuevos actores que imponen una forma diferente de apropiación del bosque en el Huitepec, así como la comunidad ambientalista de San Cristóbal y los gobiernos municipal y estatal en sus dependencias relacionadas con el medio ambiente, quienes influyen de forma indirecta en el uso de este espacio.

\section{Las Ánimas-San Francisco: de labor colonial a reserva privada}

Describiremos brevemente el caso de una de las propiedades privadas derivadas de las antiguas labores debido a su relevancia en el mantenimiento de los bosques en el Huitepec: la Labor de Las Ánimas, que a finales del siglo XIX poseía más de 270 hectáreas y era propiedad de la familia Ballinas (Pedrero, 1984). Hacia la década de los cincuenta, la labor cambió de dueños y fue adquirida por Hernán Pedrero, quien la convirtió en la Finca San Francisco, donde hacia 1970 se producían frutales que se exportaban a todo el estado; además se criaban ganado vacuno y animales exóticos.

A partir de los ochenta esta gran propiedad comenzó a fraccionarse y de ella se derivaron dos grandes predios con propósitos contrastantes: por un lado se vendió un predio de 136 hectáreas de bosque bien conservado que se convirtieron en la reserva natural Cerro del Huitepec; y adyacente a ella se vendieron poco más de 100 hectáreas de uso agrícola a indígenas tsotsiles, quienes formaron la ranchería Selva Natividad a la cual nos hemos referido en este trabajo y cuya población tuvo un rápido crecimiento. Años más adelante se vendieron áreas para fraccionamientos privados y actualmente la familia posee unas 20 hectáreas de terreno cuyo uso futuro parece encaminarse a este último fin. 
La reserva natural Cerro de Huitepec (véase el mapa 2) fue la primera reserva de tipo privado en México específicamente adquirida y destinada a la conservación. La compró un grupo de personas de la ciudad encabezadas por la organización ambientalista Pronatura Sur, A.C, quienes se encargan de manejarla y administrarla. Sus actividades están enfocadas al mantenimiento del lugar y a promover la educación ambiental entre la población urbana y las localidades cercanas. Este espacio ha sido objeto de numerosos estudios ambientales sobre la fauna y la flora del Huitepec, pues alberga un ecosistema relevante en la zona de Los Altos de Chiapas: el bosque de niebla. Se encuentra contigua a la reserva autónoma / estatal Ejido y constituye un parámetro interesante sobre el papel de la propiedad particular en el mantenimiento del bosque en espacios periurbanos: aunque no está exenta de problemas, su permanencia parece más clara que la de su vecina.

\section{El paisaje periurbano del Huitepec}

El análisis de uso del suelo del Huitepec revela la presencia de un paisaje diverso que incluye áreas arboladas, acahuales, zonas agrícolas, pastos y zonas urbanizadas, en una combinación que resulta difícil identificar en términos precisos para cada categoría (mapa 5). Según el análisis de la imagen de satélite, apenas una pequeña proporción de la zona corresponde a construcciones, caminos o suelo desnudo que se pueden categorizar como de uso urbano, pero ésta se incrementa significativamente cuando consideramos la zona definida por la presencia de calles y servicios o reconocida como tal por el municipio. ${ }^{13}$ De manera contraria, las áreas aparentemente agropecuarias disminuyen en forma relevante si se considera que ya no corresponden a ese tipo de uso, sino que forman parte de los jardines y áreas de esparcimiento de las propiedades campestres de la zona (cuadro 3). Es decir, aun cuando ya se considere integrado al área urbana, el tipo de desarrollo que hay en el Huitepec es distinto del que se observa en otras áreas de esta ciudad, y del que se encuentra en los grandes conglomerados urbanos.

13 Es el caso de la colonia de San Felipe, localidad que fue anexada a la ciudad en 1980 como colonia urbana, pero donde se presenta un uso de suelo que no es muy diferente del que existe en las localidades rurales, o del fraccionamiento Granjas de San Francisco que se estableció sobre un viejo cultivo de peras. 
CUADRO 3

Uso actual del suelo en el Huitepec, 2010

\begin{tabular}{lccc}
\hline Tipo de uso de suelo & $\begin{array}{c}\text { Superficie } \\
(\text { ha })\end{array}$ & $\begin{array}{c}\text { Cobertura según } \\
\text { clasificación } \\
(\%)\end{array}$ & $\begin{array}{c}\text { Cobertura según } \\
\text { tipo de propiedad } \\
(\%)\end{array}$ \\
\hline Bosque & 639.28 & 45.71 & 41.41 \\
Acahual & 144.62 & 10.34 & 8.81 \\
Agricultura & 322.38 & 23.05 & 14.61 \\
Pasto & 204.76 & 14.64 & 7.42 \\
Urbana & 87.56 & 6.26 & 27.75 \\
$\quad$ Rural, campestre & & & 14.56 \\
$\quad$ Compacta & & & 10.10 \\
$\quad$ Industrial, comercial y servicios & & & 3.09 \\
Total & 1398.60 & & \\
\hline
\end{tabular}

FUENTE: Elaboración propia.

En el paisaje del Huitepec hay amplios espacios verdes; puede considerarse como una matriz agroforestal caracterizada por la presencia de parches de bosques, frutales, pastizales, cultivos y jardines, además de las viviendas y construcciones. Se observa un gradiente de cambios donde las zonas más bajas, adyacentes al periférico, se han convertido en un espacio urbano, industrial, comercial y de servicios (gasolinerías, viveros, restaurantes, embotelladoras, venta de material de construcción, escuelas, colonias de alta densidad, etc.). En la parte alta están las zonas de reserva donde se mantienen las áreas compactas de bosque que aparentemente han permanecido sin cambios en su superficie en los últimos años ${ }^{14}$ de acuerdo con los resultados de Morales et al. (en prensa). En el espacio ubicado en medio de estos extremos se encuentra el territorio de las rancherías, que puede ser típicamente rural y fragmentado en la mayor parte de las cuatro secciones de Ocotal y en la parte alta de Alcanfores y Vistahermosa (viviendas rodeadas de áreas agrícolas y pecuarias, árboles y fragmentos forestales); rural compacto en Selva Natividad (viviendas compactas con pequeños traspatios, rodeadas por acahuales); campestre en las propiedades fácilmente delimitables de

${ }^{14}$ Cabe mencionar que la información presentada sobre la presencia del bosque se refiere a su superficie y no a su integridad biológica o composición (especies presentes, estructura, diversidad, etc.), que si bien son parte fundamental de su conservación, no se abordaron en este trabajo. 


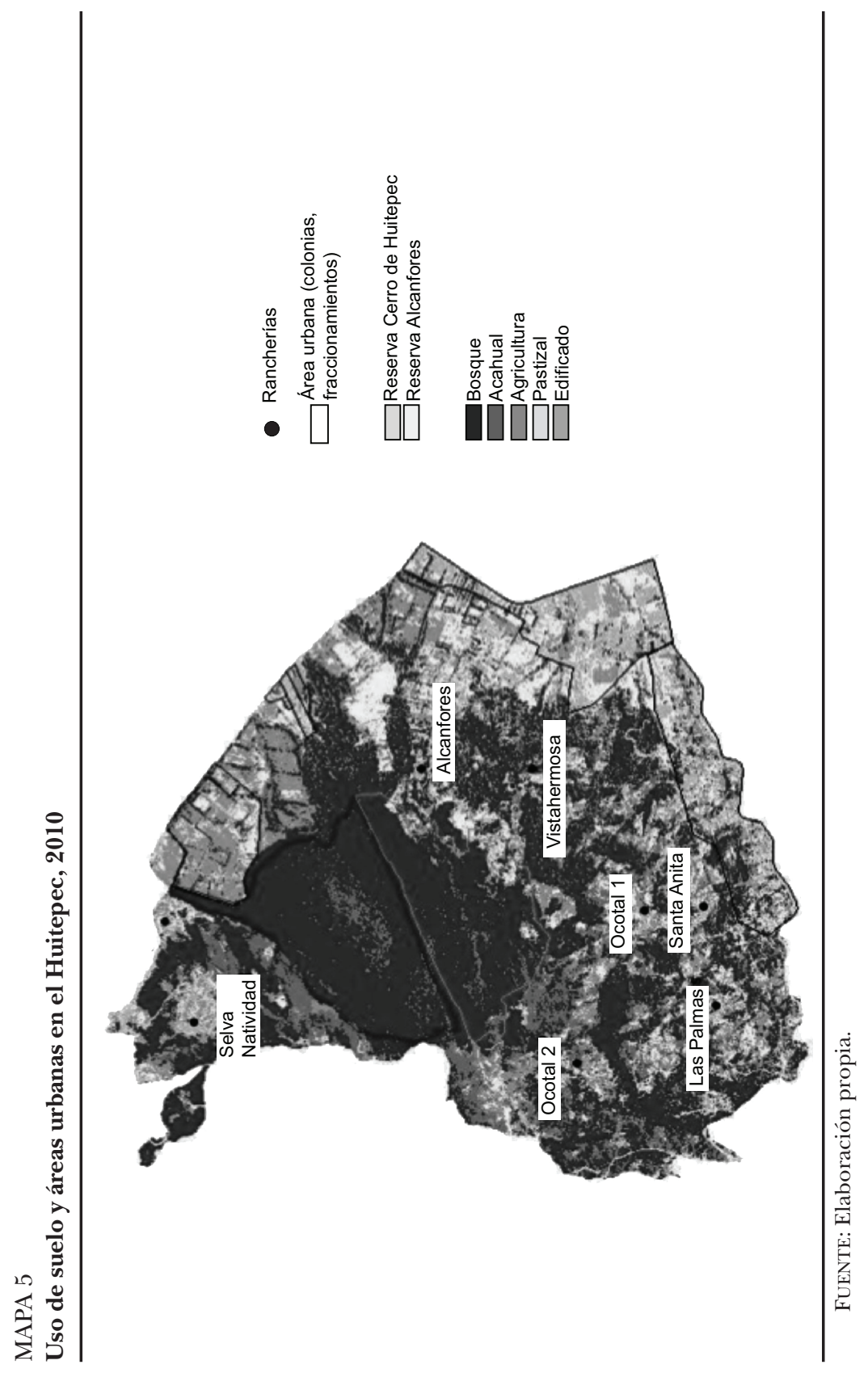


Alcanfores y Vistahermosa (viviendas con amplios jardines, pastizales y setos arbóreos), e incluso campestre-arbóreo (viviendas que tratan de mantener los elementos del bosque) en Alcanfores (mapa 5).

\section{Discusión}

El paisaje que se manifiesta actualmente en el Huitepec refleja las formas de propiedad y manejo que se han adoptado en el área a través de la historia, su relación creciente con el centro urbano, y la incidencia de los diversos actores que convergen en este lugar. Responde a la dinámica periurbana en donde la interacción de los espacios urbano y rural se manifiesta en una serie de cambios físicos y sociales que son observables tanto en las grandes ciudades como en otras de menor tamaño, aunque con manifestaciones particulares en este lugar (véase el anexo).

Se advierte un decremento en los servicios urbanos y un incremento en los servicios ambientales y los elementos arbóreos al avanzar hacia las partes más altas, y alejadas del centro urbano, que corresponde a las reservas naturales del Huitepec (Morello et al., 2003; McKinney, 2002). Las localidades rurales que están presentes en el espacio intermedio entre el área urbana y la zona de reservas mantienen jardines, huertos, cercos vivos y otras áreas de uso que se combinan con fragmentos forestales remanentes, y forman así un paisaje agroforestal que es relevante tanto para el mantenimiento de la diversidad en las áreas de reserva como para el cultivo de productos agrícolas y para la generación de servicios ambientales locales y hacia la ciudad (Goddard $e t$ al., 2010; Wu, 2008; González-García y Gómez, 2008; Morales et al., en prensa). Sin embargo cabe preguntarse ¿en qué medida su permanencia constituye una nueva forma de integración urbano-rural? o bien, ¿se trata sólo de un momento transitorio hacia su desaparición por procesos de urbanización?

La información histórica disponible nos indica que desde hace mucho tiempo el Huitepec se encuentra bajo la influencia de la ciudad de San Cristóbal: sus actividades productivas han sido orientadas en buena medida por las necesidades urbanas; los actores urbanos han adquirido posesiones en aquella zona desde hace al menos un siglo, y la ciudad ha representado una fuente de ingresos que forma parte de las estrategias económicas de la población rural de Los Altos. La nueva ruralidad de este espacio periurbano radica, como han afirmado algunos autores, en el cambio cuantitativo y cualitativo de las activida- 
des que realizan y en la dependencia de los centros urbanos; si una de las características más sobresalientes de la ruralidad era la manera en que la agricultura ordenaba la forma de vida campesina, hoy son muchas las localidades rurales carentes de agricultura y con una fuerte dependencia de las actividades manufactureras y de servicios, mientras que donde ha pervivido, la actividad agrícola ha sufrido una modificación trascendental (Arias, 2005; Benitez, 2006). En las últimas décadas la agricultura ha perdido relevancia para ordenar la vida social y económica del México rural y los elementos asociados a las formas de vida urbanas se encuentran incluso en las localidades que están distantes de los centros urbanos (Torres-Mazuera, 2009; Arias, 2005). Las localidades rurales del Huitepec reflejan la dependencia de las fuentes de trabajo urbanas, así como la especialización agrícola hacia las demandas urbanas particulares de San Cristóbal.

Por otra parte, el uso de los recursos forestales también presenta notables modificaciones, al reorientarse su función principal: de proveedor de leña y madera en beneficio de la población del Huitepec, pasó a la prestación de servicios ambientales como la captación de agua, de la cual depende la población local e incluso la urbana (De la Mora, 2010; Zárate, 2008; Estrada, 2002). La transformación de la actividad agrícola también tiene efecto sobre las áreas forestales: si bien la extensión del bosque en el Huitepec se redujo y se fragmentó en el siglo pasado, en los últimos diez años la superficie que ocupa parece no haber cambiado drásticamente. Esto puede ser resultado de la transformación de una economía agrícola que favorecía la conversión del suelo forestal a agrícola extensivo (milpa), por el abandono de esta actividad ante su baja rentabilidad y el incremento de fuentes de empleo urbano (Cortina, 2007), así como la especialización en cultivos que requieren una menor superficie (hortalizas), y en cambio necesitan el agua y el abono procedentes del bosque. Otro punto relevante es que una parte de la población urbana valora positivamente los bosques (Mcdonald, 2009), y particularmente el del Huitepec, que la ciudad percibe como un patrimonio natural, lo que parece concretarse en la presencia de áreas protegidas en este lugar (Morales et al., en prensa).

Las áreas protegidas en la zona revelan las nuevas modalidades que puede adquirir la conservación del bosque en un escenario periurbano. La Reserva Ecológica Cerro del Huitepec es una clara muestra de la incidencia urbana en el mantenimiento de áreas naturales, ya que la creación de este sitio fue resultado de la iniciativa de ciertos actores urbanos para quienes la modalidad de tenencia privada de la 
tierra fue una ventaja que hizo posible su compra; esta iniciativa ha sido efectiva al garantizar el mantenimiento del bosque en la zona. Por su parte el "Ejido" adyacente es una propiedad colectiva en la cual la poca claridad respecto a su legalidad, la diversificación social y la presión urbana por la tierra han favorecido los procesos de ocupación y apropiación irregular. Actualmente los zapatistas ejercen un control sobre el territorio que se basa más en sus redes externas (movimiento zapatista, bases de apoyo regionales, sociedad civil nacional e internacional) que en el establecimiento de acuerdos locales, a pesar de que consideran que se trata de una reserva "comunitaria". Las formas tradicionales de control local se traslapan con las nuevas perspectivas de conservación ambiental, y los actores locales asumen una u otra lógicas para asegurar su dominio del espacio (Estrada, 2002). El futuro de esta zona dependerá del tiempo en que sus ocupantes actuales puedan asegurar el control mediante su presencia, o bien de que se llegue a consolidar una propuesta de manejo que incluya la participación de los distintos actores involucrados, incluyendo a los pobladores de la ciudad.

Un tema que merece abordarse a la luz de la perspectiva de la nueva ruralidad y los espacios periurbanos es el referente al papel de las formas de propiedad y su efecto para la conservación de las áreas forestales. La investigación sobre el manejo forestal en nuestro país indica que la propiedad social y el manejo comunitario constituyen los pilares o condiciones más relevantes para el mantenimiento a largo plazo de los recursos forestales (Cortina, 2007; Merino y Barton, 2004). Sin embargo la propiedad comunal no es por sí misma garantía de un manejo efectivo, sino que requiere una serie de condiciones que determinan su éxito, las cuales están relacionadas con una claridad en la base de los recursos, los usuarios, las reglas de apropiación y la obtención de beneficios (Ostrom, 2000). Los estudios de la nueva ruralidad en espacios periurbanos indican que el crecimiento urbano acelerado, sobre todo en las grandes ciudades, ha ejercido un papel devastador sobre las formas de control social de las tierras ejidales y comunales, lo que ha llevado a su pérdida, ya sea mediante la ocupación ilegal o el fraccionamiento legalizado por los mismos ejidatarios (Aguilar y Escalona, 2000; Cruz, 1996). El surgimiento de formas "urbanas" de valoración de la tierra en un contexto periurbano propicia la incorporación de estos elementos en la apropiación del territorio, lo cual puede apuntar tanto al mantenimiento de las áreas forestales (por ejemplo en áreas protegidas) como a su pérdida (mercado de tierras) (Estrada, 2002; Salazar, 2000; Velázquez, 1997). En algunos casos las tierras co- 
munales han pervivido y se han transformado en espacios híbridos que recrean en la ciudad los elementos comunitarios y mantienen zonas agrícolas en el área urbana haciéndolas incluso exitosas (Torres-Lima y Rodríguez-Sánchez, 2008).

En el caso analizado se puede considerar que ante una propiedad social debilitada o poco clara, con la presencia de normativas urbanas y de actores diversos en un espacio, y con la puesta en juego de intereses económicos muy fuertes, la propiedad privada puede ser una forma de conservación de los recursos por exclusión que está dentro de los nuevos esquemas que apuntan a la diversificación de estrategias y a la protección privada voluntaria (Kauneckis y York, 2009). Sin embargo, tal como lo afirman Weber y Reverte (2006), "la propiedad es una herramienta entre otras cuya eficacia depende del contexto en que se instituye" (Weber y Reverte, 2006: 123). Si consideramos que la conservación debe ampliarse desde la perspectiva de la protección en reservas hasta la diversificación del paisaje en torno a éstas, es necesario tomar en cuenta la participación de los propietarios.

En el territorio de las rancherías del Huitepec no hay un procedimiento de regulación local ni municipal sobre el uso del suelo privado, por lo que éste depende de las decisiones particulares de cientos de pequeños y medianos propietarios y de pocos grandes propietarios. Para el desarrollo colectivo de los servicios urbanos se ha requerido cierta organización local que de alguna forma incide sobre la tierra y sus recursos. El caso más evidente se presenta debido a que la necesidad de agua (un recurso común) está generando acciones grupales, y en última instancia regionales, a favor del mantenimiento de áreas arboladas aún presentes y de posible recuperación (como la reforestación y los proyectos de restauración) (Zárate, 2008). Asimismo han emergido conflictos sociales entre los diversos actores (nativos y recién llegados, agricultores y no agricultores) que son característicos de los espacios periurbanos, como la disputa por el agua y la toma de decisiones (Ávila, 2009; Aguilar y Escalona, 2000). A pesar de que espacialmente la zona urbana puede ya considerarse dentro del Huitepec, los pobladores nativos mantienen y reafirman la posición de que sigue siendo una ranchería, pues esto les da un mayor control local; en cambio los pobladores urbanos manifiestan la intención de convertir el área en una colonia urbana, pero no porque se perciba que son mejores la regulación y la dependencia municipal, sino porque así habría reglas más claras de participación en la localidad, hasta ahora dominada por la población nativa. 
Por diferentes razones la urbanización del Huitepec está tomando matices distintos de los de otras zonas, pues a este lugar llegan pobladores interesados en su espacio boscoso y sus características rurales, quienes intentan mantenerlos en sus propiedades integrando nuevos elementos ecotecnológicos. Estos procesos han sido identificados en México y Europa, donde el periurbano constituye no sólo un espacio, sino una forma de vida en la que se integran elementos de sustentabilidad ambiental y organización social recreados por el imaginario urbano (Hiernaux, 2000; Banzo, 2005). De la misma manera, la vinculación de los agricultores con un mercado urbano le ha dado un nuevo vigor a esa actividad, que al combinarse con enfoques agroecológicos y de comercio justo representa una posibilidad radicalmente diferente de la producción comercial convencional de flores, también orientada por el mercado urbano, que se presenta en otras laderas del Huitepec. Estos espacios neorrurales pueden representar la posibilidad de mantener un entorno agroforestal que le dé mayor viabilidad a las áreas protegidas. Sin embargo es necesario diferenciar a los nuevos actores que llegan a este lugar con la intención de establecerse y vivir ahí, de aquellos que participan en un mercado de tierras, para quienes lo "sustentable" representa apenas una ventaja que les conviene mantener hasta que obtengan las ganancias económicas que esperan. Para el sector inmobiliario cualquier terreno adyacente a la ciudad es susceptible de anexarse a la misma. En sitios como Morelos este proceso fue tan devastador que expulsó a la población local (Ávila, 2009; Martínez, 2010). Si bien los pobladores nativos no han sido afectados pasivos del avance urbano sobre sus tierras, puesto que han participado activamente de dicho proceso y han favorecido la urbanización desde dentro de las propias localidades, la valoración económica derivada de esa urbanización está siendo capitalizada principalmente por actores externos mediante la compraventa de lotes y una mayor promoción inmobiliaria.

Todo lo anterior nos indica que en el contexto periurbano las áreas protegidas y forestales presentan características muy particulares que normalmente no se toman en cuenta desde la perspectiva de las estrategias de conservación. En este trabajo se ha planteado la posible utilidad de enfocar la nueva ruralidad a partir de una perspectiva más social que geográfica para entender su dinámica y su posible mantenimiento a largo plazo con fines de conservación. Nos propusimos, de acuerdo con C. de Grammont (2010), utilizar conceptos más específicos -como el de periurbano- para referirnos a la condición del caso 
analizado en el Huitepec. Entonces, ¿la nueva ruralidad es un concepto adecuado para analizar el problema de la conservación de espacios forestales periurbanos? Si su utilidad consiste en afirmar que todo es integral y que se han diluido las fronteras entre lo urbano y lo rural, no parece servir de mucho; sin embargo cada vez se utiliza más en distintas disciplinas el concepto de nueva ruralidad para analizar múltiples casos, lo cual permite poner problemas semejantes ante otros referentes. Del mismo modo, con el concepto de periurbano que se utiliza en este trabajo es factible identificar elementos comunes entre diferentes temáticas (aspectos agrícolas, ecológicos y sociales) que ocurren en un mismo espacio. En todo caso la nueva ruralidad permite trascender fronteras teórico-académicas más que físicas y sociales. En este análisis se ha de evidenciar la necesidad de ir más allá de la conservación de áreas relevantes mediante la protección de sitios, para adoptar esquemas adecuados a las nuevas condiciones integrales del campo y la ciudad, considerando los distintos usos de suelo, las actividades económicas, las formas de propiedad, las normas urbanas y rurales, y la participación social de diferentes actores. La protección de espacios ambientalmente relevantes en un contexto periurbano debería conducir a la creación de redes locales de participación social que tomen en cuenta a los distintos actores involucrados y sus expectativas del mismo espacio, sobre todo en un contexto en que las autoridades formales (municipales) son las grandes ausentes en las localidades.

\section{Conclusión}

El Huitepec constituye un ejemplo de los complejos procesos socioambientales por los cuales atraviesan los espacios que rodean a las urbes de cualquier tamaño. Desde la época de la Colonia el Huitepec recibía la influencia del centro urbano, pero actualmente ya es una parte plena de la ciudad, no sólo porque contiene espacios urbanizados o construidos, sino sobre todo por los espacios no edificados, que son cruciales para la viabilidad ambiental urbana (Banzo, 2005), para la producción de alimentos, y para la preservación del paisaje sancristobalense (Morales et al., en prensa).

Se puede afirmar que la presencia de áreas forestales y agroforestales en el Huitepec no sólo responde a un proceso de transición temporal hacia su desaparición debido al crecimiento urbano, ni tampoco se les puede ver como parte de un proceso de mantenimien- 
to y conservación de los recursos forestales impulsado por una comunidad rural fuertemente consolidada en un territorio. Corresponde a la integración espacial de procesos socioambientales históricos donde el bosque y la agricultura tienen un sentido y un valor específico para los actores presentes; valor y actores que de hecho también están cambiando constantemente.

Aunque los habitantes manifiestan que actualmente en el Huitepec se disfruta de un estado ideal que combina los servicios urbanos con un ambiente natural, pocos tienen la capacidad de decidir entre distintas formas de uso de suelo en sus terrenos, dado su reducido tamaño. Tampoco existen reglas locales efectivas para garantizar la permanencia futura de un paisaje diversificado en torno a las reservas, y éste depende de las decisiones de uso y de las valoraciones de cada poblador. Hasta el momento las áreas de reserva han sido efectivas para mantener el bosque, pero es preciso buscar estrategias para el espacio circundante que minimicen los efectos negativos de la urbanización sobre las áreas protegidas y les brinden cierta integridad ecológica dentro de la región (Morales et al., en prensa; Mcdonald et al., 2009). Cabe recordar que el Huitepec es sólo una sección del espacio periurbano de San Cristóbal, donde la ocupación del territorio siempre ha sido irregular y caótica. Si bien los bosques del Huitepec son muy relevantes, no son los únicos en el entorno de la ciudad, y sólo tendrán viabilidad a largo plazo en tanto estén vinculados en una escala espacial mayor con otros fragmentos de bosque en la región.

Se requiere ampliar las nociones de conservación y sustentabilidad de forma que incluyan otros espacios o esquemas fuera de la conservación típica en áreas protegidas; han de establecerse reglas y sanciones relativas al uso de suelo y al manejo que hacen los actores locales de los recursos naturales; y han de favorecerse diversos vínculos con los sectores urbanos conforme a un esquema de corresponsabilidad ambiental y social. Si bien la urbanización representa una amenaza para la protección de áreas ambientalmente relevantes, dentro de ciertas modalidades puede ser también un incentivo para su mantenimiento, y en última instancia las áreas de urbanización campestre o rural que integran elementos arbóreos, fragmentos de bosque y áreas agrícolas son una mejor opción que la urbanización compacta densamente poblada que se presenta en otras áreas del periurbano de San Cristóbal. 


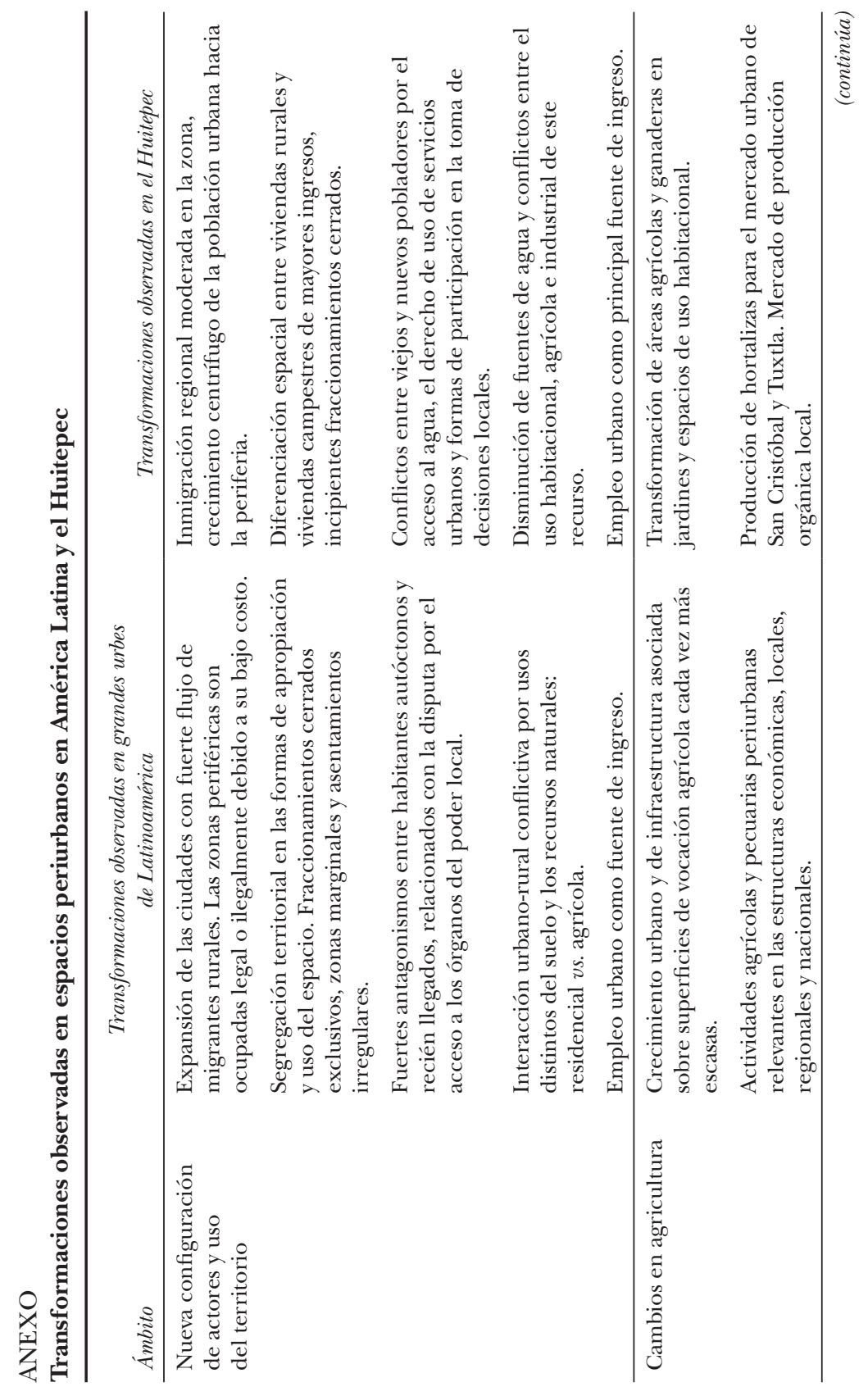




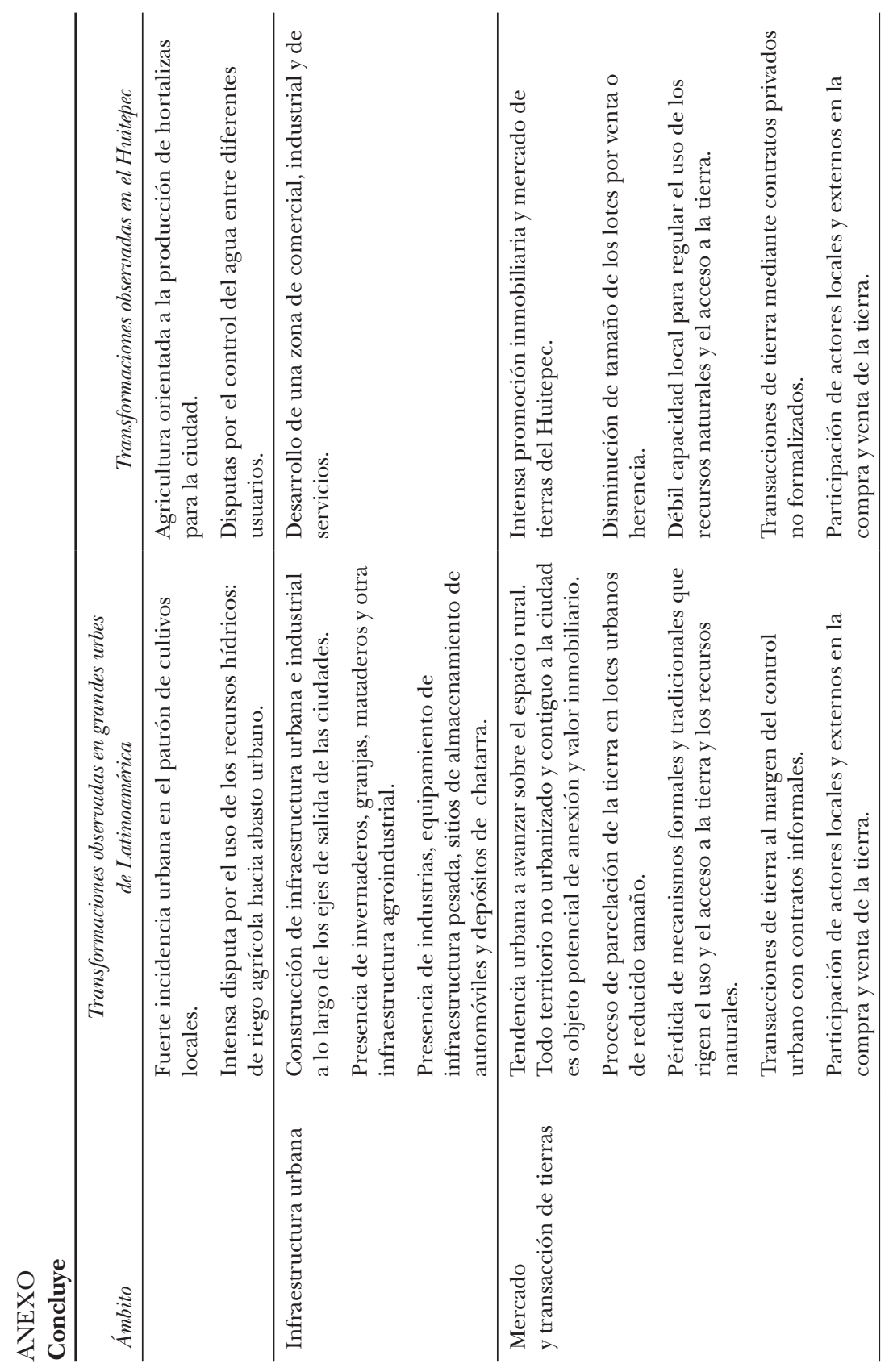




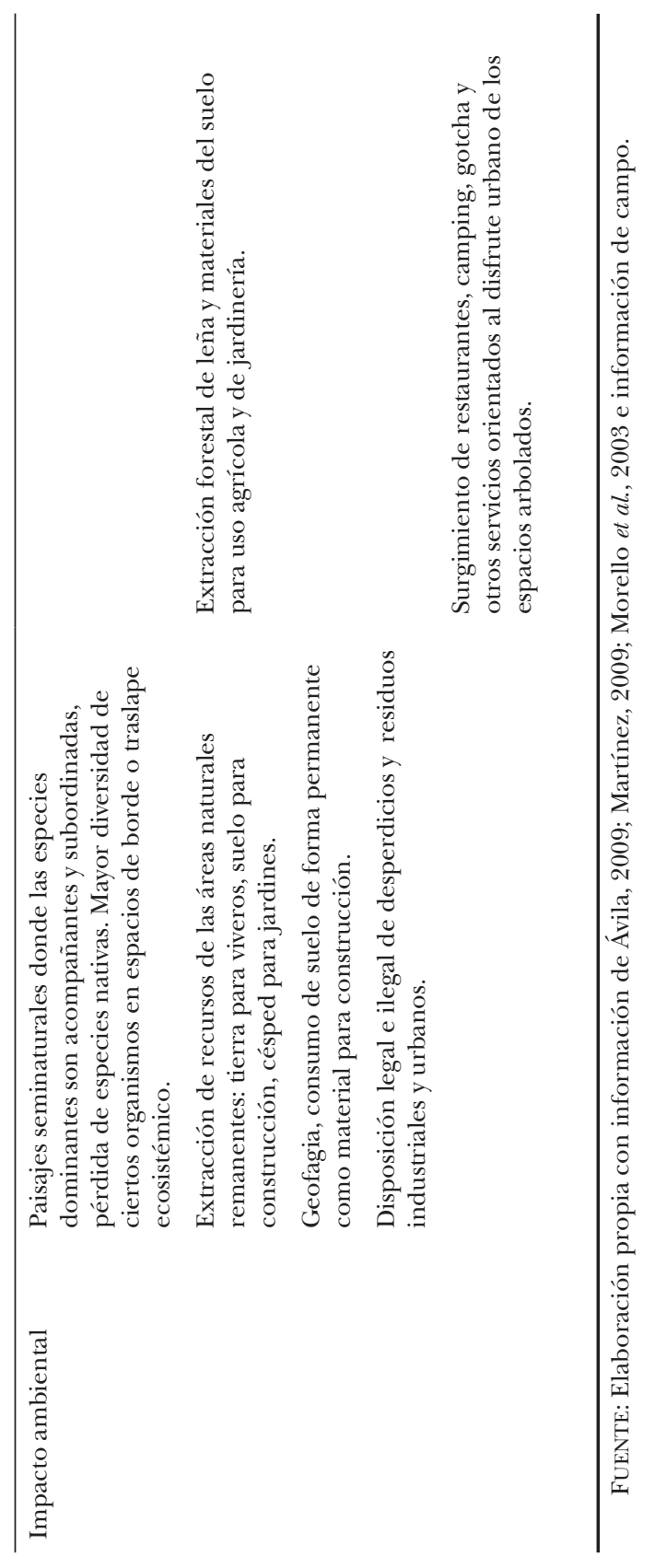




\section{Bibliografía}

Aguilar, G. y M. Escalona (2000), "Expansión metropolitana de la Ciudad de México en el ámbito rural de Texcoco”, en P. Torres-Lima (comp.), Procesos metropolitanos y agricultura urbana, México, Universidad Autónoma Metropolitana / FAO, pp. 87-103.

Arias, P. (2005), "Nueva ruralidad: antropólogos y geógrafos frente al campo hoy”, en H. Ávila Sánchez (coord.), Lo urbano-rural: ¿nuevas expresiones territoriales?, México, CRIM, UNAM, pp. 123-160.

Arriaga, L., J.M. Espinoza, C. Aguilar, E. Martínez, L. Gómez y E. Loa (coords.) (2000), Regiones terrestres prioritarias de México, México, Comisión Nacional para el Conocimiento y Uso de la Biodiversidad.

Aubry, A. (2008), San Cristóbal de Las Casas: su historia urbana, demográfica y monumental, 1528-1990, México, ADABI.

Ávila, H. (2005), "Líneas de investigación y debate en los estudios urbanorurales”, en H. Ávila (coord.), Lo urbano-rural, ¿̨nuevas expresiones territoriales?, México, CRIM, UNAM, pp. 19-58.

Ávila, H. (2009), "Periurbanización y espacios rurales en la periferia de las ciudades”, Estudios Agrarios, núm. 41, México, Secretaría de la Reforma Agraria / Procuraduría Agraria, pp. 93-123, <http://www.pa.gob.mx/ publica/rev_41/ANALISIS/7\%20HECTOR\%20AVILA.pdf $>$.

Banzo, M. (2005), "Del espacio al modo de vida. La cuestión periurbana en Europa Occidental: los casos de Francia y España”, en H. Ávila (coord.), Lo urbano-rural, ¿̇nuevas expresiones territoriales?, México, CRIM, UNAM, pp. 207-241.

Bellet, C. y J.M. Llop (2002), "Las líneas de trabajo del programa UIA-CIMES: ciudades intermedias y urbanización mundial”, Santiago de Chile, CEPAL, pp. 33-47 (Medio Ambiente y Desarrollo, 48).

Benítez, O. (2006), "Estrategias de regionalización urbano-rural desde una sociedad local: potencial para el desarrollo endógeno", Quivera, vol. 8, núm. 1, pp. 33-62.

C. de Grammont, H. (2010), "Nueva ruralidad: ¿un concepto útil para repensar la relación campo-ciudad en América Latina?”, Ciudades. Visiones integrales sobre el campo y la ciudad, núm. 85, pp. 2-6.

Conapo (2005), Sistema urbano nacional 2000-2005, México, Consejo Nacional de Población <http:/ /www.conapo.gob.mx/index.php?option=com_content\& view $=$ article $\&$ id $=3 \% 3$ Asistema-urbano-nacional-2000-2005\&catid $=25 \% 3$ Aque-es-conapo\&Itemid $=1>$.

Cortina, S. (2007), "Uso de suelo y deforestación en Los Altos de Chiapas", tesis de doctorado en Geografía, México, Universidad Nacional Autónoma de México.

Cruz, M.S. (1996), "La urbanización ejidal. El encuentro de dos procesos, el rural y el urbano", en H.C. de Gramont y H. Tejera Gaona (coords.), La 
Calderón, Soto y Estrada, ENTRE LA CONSERVACIÓN DEL BOSQUE

sociedad rural mexicana frente al nuevo milenio, vol. II, La nueva relación campo-ciudad y la pobreza rural, México, UAM / UNAM / INAH / Plaza y Valdés, pp. 123-144.

Cruz, M.S. (2002), "Procesos urbanos y 'ruralidad' en la periferia de la Zona Metropolitana de la Ciudad de México”, Estudios Demográficos y Urbanos, vol. 17, núm. 1 (49), pp. 39-76.

DeFries, R., T. Rudel, M. Uriarte y M. Hansen (2010), "Deforestation Driven by Urban Population Growth and Agricultural Trade in the Twenty-First Century", Nature Geosciences, vol. 3, núm. 3, pp. 178-181.

Estrada, M. (2002), "Cambio social y costumbres laborales: contradicciones entre uso y protección del bosque en Huitzilac, México”, Estudios Mexicanos, vol. 18, núm. 2, pp. 323-350.

García, A. (2005), "La gestión del agua en la cuenca endorreica de San Cristóbal de Las Casas, Chiapas, México", tesis de maestría en Ciencias en Desarrollo Rural Regional, México, Universidad Autónoma de Chapingo.

García-Romero, A. (2001), "Evolution of Disturbed Oak Woodlands: The Case of Mexico City's Western Forest Reserve”, The Geographical Journal, vol. 167, núm. 1, pp. 72-82.

García-Romero, A. (2002), "An Evaluation of Forest Deterioration in the Disturbed Mountains of Western Mexico City”, Mountain Research and Development, vol. 22, núm. 3, pp. 270-277.

Gobierno del Estado de Chiapas (2007), "Decreto 147 por el que se declara área natural protegida con carácter de zona sujeta a conservación ecológica el área conocida como Huitepec-Los Alcanfores", Tuxtla Gutiérrez, Gobierno del Estado de Chiapas.

Goddard, M.A., A.J. Dougill y T.G. Benton. (2010), "Scaling up from Gardens: Biodiversity Conservation in Urban Environments", Trends in Ecology and Evolution, vol. 24, núm. 2, pp. 90-98.

Godefroid, S. y N. Koedam (2003), "Identifying Indicator Plant Species of Habitat Quality and Invasibility as a Guide for Peri-Urban Forest Management", Biodiversity and Conservation, núm. 12, pp. 1699-1713.

Godelier, M. (1984), Lo ideal y lo material, Madrid, Taurus Humanidades.

González-García, A. y A. Gómez (2008), "Private Urban Greenspaces or 'Patios' as a Key Element in the Urban Ecology of Tropical Central America”, Human Ecology, núm. 36, pp. 291-300.

Gorenstein, S., M. Napal y M. Olea (2007), “Territorios agrarios y realidades rururbanas. Reflexiones sobre el desarrollo rural a partir del caso pampeano bonarense", EURE, vol. 33, núm. 100, pp. 91-113.

Grimm, N.B., H. Faeth, N.E. Golubiewski, C.L. Redman, J. Wu, X. Bai, y J.M. Briggs (2008), "Global Change and the Ecology of Cities", Science, núm. 319, pp. 756-760.

Henríquez, P. y J. L. Rangel (2009), "La reserva ecológica Huitepec”, Biodiversistas, núm. 85 , México, Conabio, pp. 6-10. 
Hiernaux, D. (2000), "Las nuevas formas metropolitanas y su relación con el mundo rural”, en P. Torres-Lima (comp.), Procesos metropolitanos y agricultura urbana, México, Universidad Autónoma Metropolitana / FAO, pp. 31-41.

INEGI (2010), Censo Nacional de Población y Vivienda 2010. Principales resultados por localidad, México, Instituto Nacional de Estadística y Geografía.

Kauneckis, D. y A.M. York (2009), "An Empirical Evaluation of Private Landowner Participation in Voluntary Forest Conservation Programs", Environmental Management, núm. 44, pp. 468-484.

Márquez, R.C. (2005), “Apropiación del territorio y gestión de recursos forestales. Estudio de caso en los ejidos de Marque de Comillas, Selva Lacandona, Chiapas", en M. Valle Rivera y E. Boege (coords.), Los actores sociales frente al desarrollo rural, tomo 1, Manejo de los recursos naturales y tecnológicos en el marco de la globalización, México, Asociación Mexicana de Estudios Rurales/Praxis, pp. 111-141.

Martine, G. (2007), Estado de la población mundial 2007. Liberar el potencial del crecimiento urbano, Washington, Fondo de Población de las Naciones Unidas.

Martínez, E. (2010), "Difusión urbana y procesos de segregación”, Ciudades, núm. 85, pp. 7-13.

Matlack, G. (1997), "Four Centuries of Forest Clearance and Regeneration in the Hinterland of a Large City", Journal of Biogeography, núm. 24, pp. 281295.

Mcdonald, R., R. Forman, P. Kareiva, R. Neugarten, D. Salzer y J. Fiser (2009), "Urban Effects, Distance and Protected Areas in an Urbanizing World", Landscape and Urban Planning, núm. 93, pp. 63-75.

McKinney, M. (2002), "Urbanization, Biodiversity, and Conservation”, BioScience, vol. 52, núm. 10, pp. 883-890.

Mera, L. (1984), "Regionalización de la subregión San Cristóbal de Las Casas, Chiapas”, tesis de licenciatura en Biología, México, Facultad de Ciencias, Universidad Nacional Autónoma de México.

Merino, L. y D. Barton (2004), La experiencia de las comunidades forestales en México, México, Instituto Nacional de Ecología.

Mora, G. de la (2010), "Servicios ambientales hidrológicos", Ciudades. Visiones Integrales sobre el Campo y la Ciudad, núm. 85, pp. 21-26.

Morales, H., M. Castillo, R. Nigh y E. Valencia (en prensa), "Conservación del Huitepec: mirando hacia afuera de la Reserva”, en La diversidad biológica de Chiapas. Estudio de estado, México, Conabio / Gobierno del Estado de Chiapas / IDESMAC.

Morello, J., S.D. Matteucci y A. Rodríguez (2003), "Sustainable Development and Urban Growth in the Argentine Pampas Region”, Annals of the American Academy of Political and Social Science, núm. 590, pp. 116-130.

Murray, S. (1993), "Gestión de la influencia de los bosques en las zonas urbanas y periurbanas”, Unasylva, Revista Internacional de Silvicultura e Industrias Fores- 


\section{Calderón, Soto y Estrada, ENTRE LA CONSERVACIÓN DEL BOSQUE}

tales, vol. 44, núm. 173, FAO: <http://www.fao.org/docrep/u9300s/u9300s03. htm\#una\%20nueva\%20visi\%C3\%B3n\%20de\%20la\%20 silvicultura.

Naranjo, E. y E. Espinoza (2001), "Los mamíferos de la reserva ecológica Huitepec, Chiapas, México”, Revista Mexicana de Mastozología, núm. 5, pp. $58-67$.

Ostrom, E. (2000), El gobierno de los bienes comunes. La evolución de las instituciones de acción colectiva, México, UNAM, CRIM / Fondo de Cultura Económica.

Parra, M. y B. Díaz (coords.). (1997), Los Altos de Chiapas: agricultura y crisis rural, tomo 1, Los recursos naturales, México, El Colegio de la Frontera Sur.

Pedrero, G. (1984), "Las haciendas y los ranchos sancristobalenses del siglo XIX. Estudio histórico", en Gobierno del Estado de Chiapas, San Cristóbal y sus alrededores, tomo I, Tuxtla Gutiérrez, SEC Chiapas, pp. 99-139.

Pedrero, G. (1987), Desarrollo histórico de la gran propiedad en el departamento de Las Casas, siglo XIX, San Cristóbal de Las Casas Chiapas, CIES.

Pedrero, G. (2010), "La nueva estructura agraria de Chiapas 1853-1910", tesis de doctorado, México, Universidad Autónoma Metropolitana.

Pronatura (1987), "Una pequeña propiedad... un paso gigante”, Pronatura, vol. 4, núm. 5, pp. 3-7.

Ramírez, B. (2005), "Miradas y posturas frente a la ciudad y el campo", en H. Ávila (coord.), Lo urbano-rural, ¿nuevas expresiones territoriales?, México, Centro Regional de Investigaciones Multidisciplinarias, UNAM, pp. 61-85.

Ramírez, N., S. Ochoa, M. González, y P. Quintana (1998), "Análisis florístico y sucesional en la Estación Biológica Cerro de Huitepec, Chiapas, México”, Acta Botánica Mexicana, núm. 44, pp. 59-85.

Ruiz, N. y J. Delgado (2008), “Territorio y nuevas ruralidades: un recorrido teórico sobre las transformaciones de la relación campo-ciudad", EURE, vol. 34, núm. 102, pp. 77-95.

Salazar, C.E. (2000), "La relación entre la población y los recursos naturales en un área de expansión de la Ciudad de México", Estudios Demográficos y Urbanos, vol. 15, núm. 2 (44), pp. 287-324.

Torres-Lima, P. y L. Rodríguez-Sánchez. (2008), "Farming Dynamics and Social Capital: A Case Study in the Urban Fringe of Mexico City”, Environment, Development and Sustainability, núm. 10, pp. 193-208.

Torres-Mazuera, G. (2009), "La territorialidad rural mexicana en un contexto de descentralización y competencia electoral”, Revista Mexicana de Sociología, vol. 71, núm. 3, pp. 453-490.

Velázquez, E. (1997), "La apropiación del espacio entre nahuas y popolucas de la Sierra de Santa Martha, Veracruz", en O. Hoffman y F. Salmerón (coords.), Nueve estudios sobre el espacio: representación y formas de apropiación, México, CIESAS / ORSTOM, pp. 113-132.

Vidal, R.M., R. Domínguez, P. Bubb y C. Macías (1999), “AICA: SE-18, Cerros alrededor de San Cristóbal de las Casas”, en H. Benítez, C. Arizmendi y L. Márquez (coords.), Base de datos de las AICAS, México, CIPAMEX / Conabio / FMCN / CCA <http:/ / www.conabio.gob.mx .México>. 
Weber, J. y J.P. Reverte (2006), "La gestión de las relaciones sociedades-naturaleza: modo de apropiación y derechos de propiedad", Revista de Geografía Agrícola, núm. 36, México, Universidad Autónoma de Chapingo, pp. 119-124.

Wu, J. (2008), “Toward a Landscape Ecology of Cities: Beyond Buildings, Trees, and Urban Forests", en M.M. Carreiro (coord.), Ecology, Planning, and Management of Urban Forests: International Perspectives, Heidelberg, Springer, pp. 10-28.

Zárate, A. (2008), "Gestión del agua y conflicto en la periferia urbana de San Cristóbal de Las Casas, Chiapas. El caso de Los Alcanfores”, tesis de maestría en Antropología Social, México, CIESAS Sureste.

\section{Acerca de los autores}

Araceli Calderón Cisneros es doctora en Ciencias en Ecología y Desarrollo Sustentable por el Colegio de la Frontera Sur; realizó estudios de maestría en Manejo de Recursos Naturales y Desarrollo Rural en la misma institución, y la licenciatura en Biología en la Universidad Nacional Autónoma de México. Se ha desarrollado en el ámbito académico y social en torno a los temas de manejo de recursos naturales, recursos forestales no maderables, tecnologías alternativas, desarrollo sustentable y nueva ruralidad, temáticas que aborda desde la perspectiva de género y las metodologías participativas, principalmente en localidades indígenas del estado de Chiapas.

Lorena Soto Pinto es doctora en Ciencias por la Universidad Nacional Autónoma de México y maestra en Ciencias Agropecuarias y Recursos Naturales Renovables por el CATIE (Costa Rica), donde obtuvo mención honorífica. Es miembro de la Academia Mexicana de Ciencias y pertenece al Sistema Nacional de Investigadores, nivel II. Sus áreas de interés son: agroforestería comunitaria; sistemas agrícolas que incorporan árboles como alternativa para la producción y la conservación de los recursos; servicios ecosistémicos; diagnóstico y diseño de sistemas agroforestales; y usos de los árboles para mejorar las unidades domésticas y el ambiente.

Erin Estrada Lugo es doctora en Antropología Social por la Universidad Iberoamericana, con mención honorífica a la mejor tesis de doctorado 2005. Es maestra en Ciencias con especialidad en Botánica por el Colegio de Posgraduados con el Dr. Efraím Hernández Xolocotzi; su tesis 
"El Códice Florentino: su información etnobotánica" tuvo mención honorífica y fue ganadora del concurso del Programa Conmemorativo del Xxx Aniversario de la Fundación del Colegio de Postgraduados en 1989. Es licenciada en Biología por la Universidad Autónoma de México. Pertenece al Sistema Nacional de Investigadores, nivel I. Sus áreas de interés son: organización social y apropiación del territorio en el uso de los recursos naturales en las sociedades campesinas indígenas; familia, grupo doméstico y parentesco; y normas locales y derecho consuetudinario maya. 
